\title{
Semantic interference in immediate and delayed naming and reading: Attention and task decisions
}

\author{
Vitória Piai*, Ardi Roelofs, Herbert Schriefers \\ Donders Institute for Brain, Cognition and Behaviour, Centre for Cognition, Radboud University Nijmegen, The Netherlands
}

\section{A R T I C L E I N F O}

\section{Article history:}

Received 27 April 2010

revision received 20 January 2011

Available online 18 February 2011

\section{Keywords:}

Attention

Naming

Reading

Task decision

Picture-word interference

\begin{abstract}
A B S T R A C T
Disagreement exists about whether lexical selection in word production is a competitive process. Competition predicts semantic interference from distractor words in immediate but not in delayed picture naming. In contrast, Janssen, Schirm, Mahon, and Caramazza (2008) obtained semantic interference in delayed picture naming when participants had to decide between picture naming and oral reading depending on the distractor word's colour. We report three experiments that examined the role of such task decisions. In a single-task situation requiring picture naming only (Experiment 1 ), we obtained semantic interference in immediate but not in delayed naming. In a task-decision situation (Experiments 2 and 3 ), no semantic effects were obtained in immediate and delayed picture naming and word reading using either the materials of Experiment 1 or the materials of Janssen et al. (2008). We present an attentional account in which task decisions may hide or reveal semantic interference from lexical competition depending on the amount of parallelism between task-decision and picture-word processing.
\end{abstract}

(c) 2011 Elsevier Inc. All rights reserved.

\section{Introduction}

Competition has been widely regarded in the cognitive neurosciences as an important mechanism in human cognition. Across different psychological domains, such as language comprehension (e.g., Norris, 1994), cognitive control (e.g., Miller \& Cohen, 2001), visual perception (e.g., Desimone \& Duncan, 1995), and motor control (e.g., Jeannerod, 1997), competition has been taken as a mode of operation fundamental to the workings of these cognitive processes. Similarly, in the field of spoken word production, competition has long been assumed to be the mechanism underlying lexical selection (Levelt, Roelofs, \& Meyer, 1999; Roelofs, 1992). Recently, however, Caramazza and colleagues (e.g., Finkbeiner \& Caramazza, 2006a,

\footnotetext{
* Corresponding author. Address: Radboud University Nijmegen, Donders Institute for Brain, Cognition and Behaviour, Centre for Cognition, Spinoza Building B.01.05, Montessorilaan 3, 6525 HR Nijmegen, The Netherlands.

E-mail address: V.Piai@donders.ru.nl (V. Piai).
}

2006b; Janssen et al., 2008; Mahon, Costa, Peterson, Vargas, \& Caramazza, 2007) argued against the assumption of competition in lexical selection in word production. In this article, we start by briefly reviewing the evidence for competition in word production and its challenge put forward by Janssen et al. (2008), based on evidence they obtained in delayed-response experiments where participants had to decide between picture naming and word reading on each trial. Next, we point out a potentially problematic characteristic of the task-decision procedure of Janssen et al. (2008). We present the results of three new experiments examining immediate and delayed picture naming and word reading and the role of task decisions.

Important evidence taken to be in favour of competition in word production comes from the semantic interference effect obtained with the picture-word interference (PWI) paradigm (e.g., Lupker, 1979; Rosinski, 1977; Schriefers, Meyer, \& Levelt, 1990). In this paradigm, the participants' task is to name a picture while ignoring a visual distractor word superimposed onto the picture (or, in the auditory version of the PWI paradigm, while ignoring auditory 
distractors presented together with the picture). Participants are slower to name pictures (e.g., arm) when the distractor has a semantic categorical relation with the picture (e.g., leg) than when the distractor is semantically unrelated to the picture (e.g., train). Given that this effect only emerges when speakers have to access the picture name, as opposed to responding manually to the picture or to reading the distractor word, the semantic interference effect is taken to arise during lexical access (Schriefers et al., 1990). Moreover, given that the effect is one of interference rather than facilitation, lexical selection has been taken to be a competitive process (Levelt et al., 1999; Roelofs, 1992; Starreveld \& La Heij, 1996). Under the lexical competition account, names corresponding to semantically related concepts become activated through spreading activation via a conceptual network and compete for selection. In the case of semantically related distractors, their activation is further increased by their presence in the input and augments the competitive process. This increased competition surfaces as longer naming latencies for pictures in the presence of semantically related distractors relative to semantically unrelated distractors. Thus competition operates such that the activation of the target node relative to the activation of other activated candidates is determinant for the accuracy and speed of selection of the target. It should be noted that the picture-word interference paradigm not only taps into lexical selection but also into attentional mechanisms (e.g., Roelofs, 1992, 2003; Starreveld \& La Heij, 1996).

Caramazza and colleagues advanced an alternative, non-competitive account for the semantic interference effect, thereby challenging the assumption of lexical competition. According to their "response exclusion" hypothesis (Finkbeiner \& Caramazza, 2006a, 2006b; Janssen et al., 2008; Mahon et al., 2007), the semantic interference effect arises after lexical selection, close to articulation onset. Visual and auditory distractor words are assumed to be available to the articulators before picture names are (e.g., Roelofs, 2003). According to the response exclusion hypothesis, phonologically specified production-ready representations are kept in an output buffer, which is assumed to be capable of holding only one representation at a time. When participants are presented with a picture and a distractor word simultaneously, the distractor word is the first item to fill the output buffer. In order to produce the name of the picture, the distractor word needs to be excluded from the buffer before picture naming can take place. Note that this exclusion process could involve a competition between the response occupying the buffer and the response seeking to gain access to it. However, in this case, the competition is at play at a late stage, close to articulation onset, whereas the lexical competition hypothesis maintains that competition plays a role at an earlier stage, during lexical selection.

One core assumption of the response exclusion account is that the decision process excluding a word from the output buffer has semantically interpreted information at its disposal. Excluding the distractor from the output buffer costs time and will become more difficult, hence take longer, if the distractor word shares criteria that must be met by the response to be given. Relevant criteria that must be fulfilled, in this account, include the provenance of the production-ready representation (whether it was a picture or a word), the word class, and the semantic category the representation belongs to, among other criteria. Under this view, the semantic interference effect originates from this exclusion process: Semantically related distractor words will take longer to be excluded from the buffer than will semantically unrelated words because the former share a response relevant criterion (i.e., semantic category) with the picture name.

Important evidence for the response exclusion hypothesis comes from Janssen et al. (2008). Janssen and colleagues introduced a modified version of the PWI paradigm requiring immediate and delayed responses. In a delayed-response task, participants are instructed to delay their responses until a specific cue is given. In Janssen et al.'s delayed condition, the cue to respond was the colour of the distractor word, indicating whether participants had to name the picture or read the distractor aloud. The rationale of delayed naming is that the picture name will be retrieved upon presentation of the picture but it will be withheld from production until the cue is given. Participants took part either in the delayed condition or in the immediate condition. In half of the trials, participants named the picture and in the other half of the trials, they read the distractor word aloud. For the sake of simplicity, we use the term "naming" as a shorthand for "picture naming" and "reading" for "distractor word reading" from here onwards.

To be able to assess whether participants in the delayed condition indeed prepared the naming responses, the picture-name frequency was manipulated. The frequency effect is a well established effect in the word production literature (Balota \& Chumbley, 1985; Jescheniak \& Levelt, 1994; Oldfield \& Wingfield, 1965): Pictures with high-frequency names are named faster than pictures with lowfrequency names. However, with delays longer than $1000 \mathrm{~ms}$, the frequency effect disappears (Balota \& Chumbley, 1985). This frequency effect has been shown to be a lexical effect (Bonin \& Fayol, 2002; Jescheniak \& Levelt, 1994). From the forty pictures used by Janssen et al., half had low-frequency names and half high-frequency names.

The lexical competition hypothesis predicts semantic interference in immediate naming but not in delayed naming. In delayed naming, the distractor will not enter in competition with the picture name for selection because the name has already been selected before the distractor is presented. In contrast, according to the response exclusion hypothesis, semantic interference should be obtained both in immediate and delayed naming because the distractor needs to be excluded from the output buffer in both cases.

In line with the predictions of the response exclusion hypothesis, Janssen and colleagues (2008) found semantic interference for both immediate and delayed naming. Moreover, the semantic interference effect in the delayed condition was accompanied by the lack of a frequency effect, which was present in immediate naming. The absence of a frequency effect in delayed naming indicates that the lexical representation of the picture name had already been retrieved when the cue to produce the picture name was given. As the authors argue, the fact that the semantic 
interference effect is still found in the delayed condition challenges the lexical competition account: As the picture name has been retrieved before the distractor has been presented, the latter cannot have entered the competition process. Therefore, the semantic interference effect cannot be reflecting this competition and, thus, is not informative about the properties of lexical access. On the contrary, as they argue, if semantic interference arises post-lexically due to shared response criteria, then delaying the articulation of the picture name should not matter as the distractor word still needs to be excluded from the output buffer. Consequently, one should observe semantic interference in delayed naming as well, as Janssen et al. did.

However, Mädebach, Oppermann, Hantsch, Curda, and Jescheniak (in press), using Janssen et al.'s materials and a design nearly identical to Janssen et al.'s experiments, failed to replicate the semantic interference effect in delayed naming while obtaining the same pattern of frequency effects as Janssen et al. (Experiments 1, 3 and 5). Surprisingly, Mädebach et al. also failed to obtain semantic interference in immediate naming using Janssen et al.'s task (Experiment 5). However, the same set of materials yielded a sizeable semantic interference effect using the standard PWI paradigm (Experiments 2, 4 and 6). Mädebach et al. concluded that the semantic interference effect found by Janssen et al. is not of the same nature as the interference effect usually found with the PWI paradigm. Accordingly, using results obtained with Janssen et al.'s task to reject the competition account is not justified. However, Mädebach and colleagues did not test delayed naming without task decisions. Moreover, they do not explain why the semantic interference effect is absent in immediate naming using Janssen et al.'s paradigm. According to the competition hypothesis, competition should have played a role in lexical selection in immediate naming, thereby leading to longer RTs in the semantically related condition than in the unrelated condition. In the next section, we describe an account that explains the difference in results between studies with respect to immediate naming in terms of the task decisions required in the paradigm of Janssen et al. (2008).

\section{A task-decision account}

In a standard PWI experiment, participants know they have to name the pictures. Janssen et al. (2008), however, used a task-choice procedure (cf. Besner \& Care, 2003) in which participants have to decide which task to perform online and at every trial. The colour of the distractor word determines whether the picture has to be named or whether the distractor word has to be read aloud. This change in the paradigm appears to be so minimal that it makes one believe it still is straightforwardly comparable to the standard PWI paradigm. However, the fact that task decisions need to be made raises an issue of attentional control, namely how task decisions and picture-word processing are coordinated.

Based on findings obtained in the context of the psychological refractory-period (PRP) paradigm used in examining dual-task performance (Pashler, 1994; Pashler \& Johnston,
1989), it has been argued that, when participants plan words in the context of a concurrent task, they set a criterion concerning the amount of overlap allowed between the tasks (Meyer \& Kieras, 1997a, 1997b; Roelofs, 2007, 2008a). So although two stimuli may be identified in parallel, some processes of each task cannot occur simultaneously, forcing certain computations for the second task to wait until computations for the first task are accomplished (see also Sigman \& Dehaene, 2008). The period during which processing of the second task has to wait for the other task is commonly known as cognitive slack. Some effects usually observed in a single-task situation may disappear in a dual-task situation because the processing time associated with that effect is absorbed into the cognitive slack (e.g. Pashler \& Johnston, 1989). The PRP paradigm and the taskchoice paradigm differ in the extent to which participants know what task to perform at a specific point in time (see Besner \& Care, 2003): The task is known beforehand in the PRP case whereas in the task-choice paradigm, choices are made at every trial. It has been shown that this decision process is not trivial, requires attention and can take hundreds of milliseconds to be completed (Paulitzki, Risko, O'Malley, Stolz, \& Besner, 2009).

In Janssen et al.'s paradigm, there are two major processing streams: The language processes, involved in picture naming and word reading, and a task-decision process, responsible for deciding which task to perform. Allowing the language processes to proceed with the input of both the picture and the distractor until the end, i.e., until articulation, would be problematic since only one response is required. So clearly, the language processes need to be suspended at a certain point until participants know which task to perform. However, they only know which task to perform after the task-decision process, based on colour identification, has been completed. This means that although participants may allow some amount of picture-word processing to run in parallel with the taskdecision process, at a certain point the language processes have to be suspended until the task-decision process is finished. A candidate moment at which participants may choose to suspend the language processes is when lexical selection has taken place, and before word-form encoding starts (see Fig. 1; word-form encoding refers to the processes of morphological encoding, phonological encoding, and phonetic encoding). The suggestion of this moment as a potential suspension point is motivated by the observation that word-form encoding in both picture naming and reading aloud has been shown to require attention (Reynolds \& Besner, 2006; Roelofs, 2008a). Since the task-decision process also requires attention (Paulitzki, Risko, O'Malley, Stolz, \& Besner, 2009), it is plausible that participants would suspend the naming and reading processes before word-form encoding to be able to allocate attentional resources to the task-decision process.

The competition account assumes that semantic interference arises because of the delay in selecting a word in the semantically related condition relative to the unrelated condition. Panel A of Fig. 1 shows the assumed stages of picture naming and the source of differential RTs for the semantically related and unrelated conditions in the standard PWI paradigm. Indefrey and Levelt (2004) estimated 


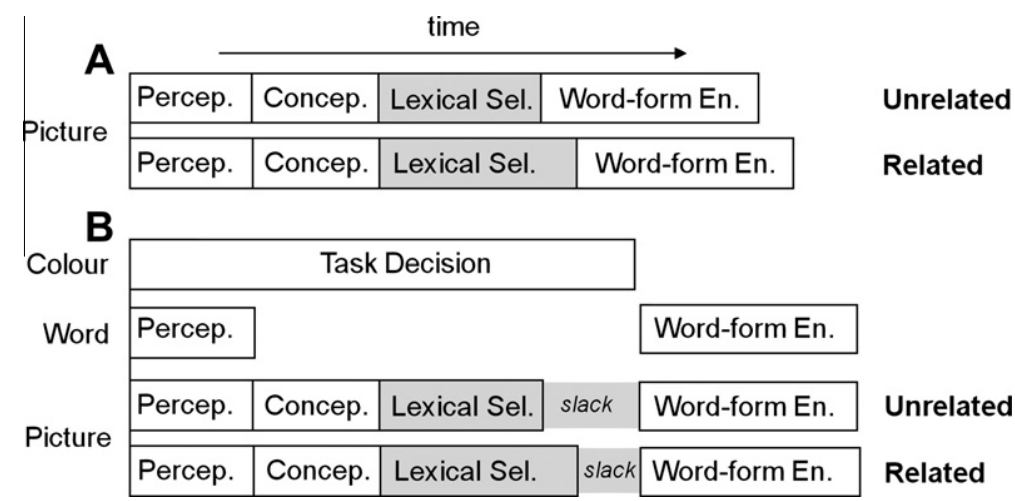

Fig. 1. Schematic illustration of the slack logic. Each box represents one processing stage. Panel A illustrates picture naming without task decisions. Panel B illustrates picture naming or word reading with a concurrent task-decision process. Percep. = perception; concep. = conceptualising; lexical sel. = lexical selection; word-form en. = word-form encoding. The distractor conditions are given in bold to the right of the figure .

that lexical selection in picture naming may be completed within some $250 \mathrm{~ms}$ after picture onset. Moreover, Paulitzki, Risko, O’Malley, Stolz, and Besner (2009) estimated that task decisions may take some 200-300 ms. If the task-decision process takes longer than the language processes up to and including lexical selection, the language processes will have to wait for the output of the task-decision process. That the language processes have to wait for the task-decision process follows naturally from the fact that participants can only respond after they know which task they have to perform. Consequently, lexical competition may be resolved during the cognitive slack created by the task-decision process, as Panel B of Fig. 1 shows. Once the task-decision process has delivered an output and participants know they should continue with picture naming, this process will resume from word-form encoding onwards. However, the difference in RT between the semantically related and unrelated conditions caused by competitively selecting a word will have been absorbed into the cognitive slack and will no longer be reflected in the net RTs, as Mädebach et al. observed. If there is no cognitive slack to absorb the longer lexical selection duration for semantically related distractors (e.g., because task decisions are completed before lexical selection is finished), semantic interference will be visible in the RTs, as Janssen et al. observed. Similarly, it has been observed that manual responding to a tone diminishes semantic interference effects from distractor words in concurrent picture naming at short compared to long SOAs in a PRP experiment (Dell'Acqua, Job, Peressotti, \& Pascali, 2007). As Dell'Acqua et al. argued, this finding suggests that manual responding to a tone may create cognitive slack, which may absorb the semantic interference effect.

In short, our hypothesis is that semantic effects will surface in the RTs if the duration of the stages in the picture naming process up to and including lexical selection in the related condition is longer than the duration of the task-decision process. Note that the amount of cognitive slack required to absorb lexical selection differences does not have to be large: Semantic context effects usually have a magnitude of 30-40 ms. This means that a difference of some $40 \mathrm{~ms}$ between the task-decision and the picturenaming processes is already enough to render the effect measurable or not. If task decisions took slightly less time in the study of Janssen et al. than in that of Mädebach et al., the difference in results between these studies is readily explained. Note that the task-decision account is compatible with the lexical competition account, but not with the response exclusion account. This is because a response cannot be excluded before the task is known, thus response exclusion cannot take place in parallel with the task-decision process. Consequently, semantic interference arising from response exclusion cannot be absorbed into the slack created by the task-decision process.

To sum up, the present study focuses on two major issues: the role of task decision in immediate picture-naming and whether semantic effects are present in delayed picture naming. Note that these two issues are tightly related: Janssen et al. make a claim against competitive lexical selection by showing semantic interference in delayed naming. But in their experiments, they used a task-decision paradigm. Accordingly, investigating either only task decision or semantic effects in delayed naming addresses the issues raised by the evidence of Janssen et al. only partially. Consequently, these two issues are better studied in combination.

\section{Plan of the present study}

In Experiment 1, participants did not have to make task decisions: They were instructed to name the pictures only and to ignore the distractor words. Pictures were named in both immediate and delayed conditions by the same participants (Janssen et al. tested the conditions between participants). Given that there are no task decisions, the competition hypothesis predicts semantic interference in immediate but not in delayed naming. In contrast, according to the response exclusion account, semantic interference should be obtained in both immediate and delayed naming.

In Experiment 2, we introduced task decisions and we tested for semantic interference in both immediate and delayed naming using the design and materials of Janssen et al. (2008) translated into Dutch. We recorded both naming and reading RTs (Janssen et al. and Mädebach et al. report only naming RTs). Half the trials required naming and the other half required reading. Participants performed 
both immediate and delayed tasks. According to our taskdecision account, depending on the relative speed of picture naming and task-decision processes, semantic interference should be present or absent in immediate naming. Moreover, semantic interference should always be absent in delayed naming and in reading (Glaser \& Düngelhoff, 1984; Glaser \& Glaser, 1989; Roelofs, 1992, 2003). In contrast, under the response exclusion account, semantic interference should be obtained for immediate and delayed naming, and reading in the delayed condition. According to the response exclusion hypothesis, written words obligatorily enter the articulatory buffer and overwrite buffered responses (Finkbeiner \& Caramazza, 2006a). However, this would entail that prepared and buffered picture names are overwritten by the written word and that the picture name has to be planned again in the delayed condition. This should yield both a semantic interference effect and a frequency effect, contrary to what Janssen et al. (2008) observed. Therefore, we assume that written words engage the response exclusion process rather than overwrite buffered naming responses. This predicts semantic effects in word reading.

In Experiment 3, we tested semantic interference in delayed naming and reading with the same materials as in Experiment 1. We increased the proportion of naming trials in the experiment from $50 \%$ (as in previous studies and in Experiments 1 and 2) to 75\%, making it even more likely that participants would prepare their naming responses. Again, we recorded both naming and reading RTs. According to the competition hypothesis, semantic interference should be found neither in naming nor in reading. According to the response exclusion account, on the contrary, semantic interference should be found for both reading and naming, especially in the $75 \%$ naming condition.

To extend our analyses and to increase their sensitivity, besides the standard statistical tests based on averaged RTs, we also conducted RT distributional analyses on the data of the three experiments. The use of averaged RTs has the disadvantage of concealing a possible mixture of different underlying effects. Latency distribution analyses may reveal these tradeoffs (e.g. Lamers \& Roelofs, 2007; Roelofs, 2008b; Yap \& Balota, 2007) as they examine the shapes of whole distributions. We performed both Vincentile and ex-Gaussian analyses. In Vincentile analyses (cf. Ratcliff, 1979), group RT distributions are examined. ExGaussian analysis, in turn, characterizes an RT distribution by assuming an explicit function for the shape of the distribution (e.g., Heathcote, Popiel, \& Mewhort, 1991; Luce, 1986; Ratcliff, 1979; Yap \& Balota, 2007). The ex-Gaussian analysis provides three parameters characterizing a distribution: $\mu$ and $\sigma$, reflecting the mean and standard deviation of the Gaussian portion respectively, and $\tau$, reflecting the mean and standard deviation of the exponential portion. The mean of the whole distribution equals the sum of $\mu$ and $\tau$ (with a few milliseconds rounding error in estimations).

Heathcote et al. (1991) showed that effects that are absent in mean RTs may nevertheless be present as opposing effects in the ex-Gaussian components (e.g., as facilitation in $\mu$ and interference in $\tau$, cancelling each other out in the mean RTs). Thus, it is important to assess whether effects that are absent in mean RTs, as the competition hypothesis predicts for semantic interference in delayed naming and reading, are nevertheless present in components of the RT distributions. Vincentile and ex-Gaussian analyses allow one to explicitly test for these possibilities. To our knowledge, this study is the first one to extensively use different RT distribution analyses to investigate the semantic interference effect in the PWI paradigm (for an analysis of semantic facilitation, see Roelofs, 2008b).

\section{Experiment 1}

In our first experiment, no task decisions had to be made: Participants always named the pictures while ignoring the distractor words. To ascertain that participants were nevertheless processing the distractor word in delayed naming, a distractor-word verification task was introduced: At the end of each trial, a verification word was shown. Participants had to indicate whether the verification word and the distractor were the same or not by pressing one of two buttons. To make the immediate and delayed conditions as similar as possible, the verification task was introduced for both conditions. Different from Janssen et al. (2008), our participants always performed both immediate and delayed naming.

Janssen et al. presented the pictures continuously until trial offset in their delayed condition. We opted for having the presentation duration of the pictures restricted to $250 \mathrm{~ms}$. With a restricted presentation of the picture, participants are pressed to select the picture name at picture presentation. Moreover, they are less likely to re-engage in lexical selection since the picture is no longer visible to them.

In the absence of task decisions, the competition hypothesis predicts semantic interference in immediate but not in delayed naming, whereas the response exclusion account predicts semantic interference in both immediate and delayed naming.

\section{Method}

\section{Participants}

Eighteen young adult participants ( 2 male) from the participant pool of Radboud University Nijmegen participated in the experiment for compensation of 7.5 Euros. All participants were native speakers of Dutch with normal or corrected-to-normal vision.

\section{Materials and design}

Thirty-two pictures were selected from the picture database of the Max Planck Institute for Psycholinguistics, Nijmegen, together with their basic-level names in Dutch. This selection consisted of pictures of objects from eight different semantic categories with four objects pertaining to each category. A list of the materials can be found in Appendix A. Additionally, four pictured objects were selected as practice items. These were taken from two semantic categories which were different from the eight experimental categories. All pictures were white line drawings on a black background, scaled to fit into a frame 
of $10 \mathrm{~cm} \times 10 \mathrm{~cm}$. The words were presented in font Arial size 36.

Each target picture was combined with a word from the same semantic category (related condition) and with a word from a different semantic category (unrelated condition) by re-pairing the pictures with different distractors, yielding 64 picture-distractor pairs. This first independent variable is referred to as distractor type (related, unrelated). The manipulation of distractor type was varied within participants and within items. Distractor words were presented in white and they were members of the response set. The second independent variable was response mode (immediate, delayed). Three different inter-stimulus intervals (ISI) were used: $0 \mathrm{~ms}$ (immediate naming condition) and $1000 \mathrm{~ms}$ or $1500 \mathrm{~ms}$ distractor post-exposure (delayed naming condition). The 64 picture-distractor pairs appeared once at 1000 -ms and once at 1500 -ms ISIs, and twice at 0 -ms ISI. Trials were blocked by response mode (i.e., immediate vs. delayed). In the case of the delayed naming condition, both ISIs were presented in random order.

Verification words were presented in yellow (RGB: $255,255,0$ ) on a black background. For each trial, the verification word could be either identical to the distractor (identical condition) or different (different condition). In the latter case, the verification word was always semantically unrelated to both the picture and the distractor but still belonged to the response set. The 64 picture-distractor pairs in the immediate naming condition were combined once with 64 verification words from the identical condition, and once with a word from the different condition. Similarly, 32 pairs from the $1000-\mathrm{ms}$ ISI and 32 pairs from the 1500-ms ISI conditions were combined with a verification word of the identical condition and the remaining 32 pairs in each of these two ISIs, with a verification word of the different condition. In total, each response mode block consisted of 128 trials, which were presented in random order with one unique list per participant. The items were randomised using Mix (van Casteren \& Davis, 2006) following two constraints: A given picture or a given distractor could not appear in consecutive trials. Participants took part in both the immediate and the delayed naming conditions and the order of the response mode conditions was counterbalanced across participants.

\section{Procedure and apparatus}

Participants were seated in front of a computer monitor (screen resolution: $1280 \times 1024$ ), approximately $50 \mathrm{~cm}$ away from it. The presentation of stimuli and the recording of responses were controlled by Presentation Software (Neurobehavioral Systems, Albany, CA). Vocal responses were measured with a voice key. Before the experiment, participants were familiarised with the pictures and the names to be used in the experiment. They were instructed to name the picture upon the presentation of the distractor word and to give a manual response indicating "yes" or "no" upon the presentation of the verification word. Next, a block of eight practice trials was presented according to the response mode condition, followed by the experiment proper.

For the immediate block, participants were instructed to name the picture and to ignore the distractor word. For each trial in the immediate condition, a black screen was presented for $500 \mathrm{~ms}$ followed by the display of the picture-distractor pair, which remained on the screen for $250 \mathrm{~ms}$. A black screen followed for $2250 \mathrm{~ms}$. Next, the verification word appeared on the screen for $250 \mathrm{~ms}$ followed by a black screen for $2250 \mathrm{~ms}$. For the delayed block, participants were instructed to name the picture only upon presentation of the distractor word, which always appeared after the target picture. For each trial, a black screen was presented for $500 \mathrm{~ms}$ followed by the presentation of the picture. The picture remained on the screen for $250 \mathrm{~ms}$ followed by a black screen for $1000 \mathrm{~ms}$ or $1500 \mathrm{~ms}$, depending on the ISI of the respective trial. Next, the distractor word was presented for $250 \mathrm{~ms}$ followed by a black screen for $2250 \mathrm{~ms}$. Then the verification word was displayed for $250 \mathrm{~ms}$ followed by a black screen for $2250 \mathrm{~ms}$. An example of the trial structures can be found in Fig. 2. The registration of the vocal and manual responses started as soon as the distractor word and the verification word, respectively, were displayed on the screen and lasted $2500 \mathrm{~ms}$. The target pictures, the distractors and the verification words always appeared in the centre of the screen. The whole experimental session lasted approximately $30 \mathrm{~min}$.

\section{Analysis}

After each trial, the experimenter evaluated the participants' vocal responses. Responses which contained a disfluency, a wrong pronunciation of the word, a wrong response word, or triggering of the voice key by a sound which was not the participant's response were coded as errors and subsequently excluded from the statistical analyses of the naming RTs. Naming RTs and verification RTs shorter than $100 \mathrm{~ms}$ were also excluded from the analyses. RTs were submitted to by-participant $\left(F_{1}\right)$ and by-item $\left(F_{2}\right)$ analyses of variance with response mode and distractor type as independent variables. Furthermore, $m i n F^{\prime}$ (Raaijmakers, Schrijnemakers, \& Gremmen, 1999) was computed for the effects of distractor type only if both $F_{1}$ and $F_{2}$ reached significance. Additional post-hoc frequency analyses were conducted with by-participant and by-item ANOVAs with response mode, frequency of the pictures' names and distractor type as independent variables. For the relevant comparisons, involving distractor type, 95\% confidence intervals are provided in addition to the results of the ANOVAs. Errors were submitted to logistic regression analyses (cf. Jaeger, 2008). Ex-Gaussian parameters were analysed with dependent $t$-tests. Since we predict semantic interference in immediate naming, one-tailed t-tests were used.

\section{Results}

\section{Mean naming RTs}

Table 1 shows the means of the naming RTs for the immediate condition and the collapsed delayed condition. First, we split the naming RTs into trials with correct vs. incorrect subsequent verification responses. No effect of accuracy in the naming RTs was found nor any interactions with response mode or distractor type, all $F s<1$. Therefore naming RTs were analysed independently of accuracy in the verification task. 

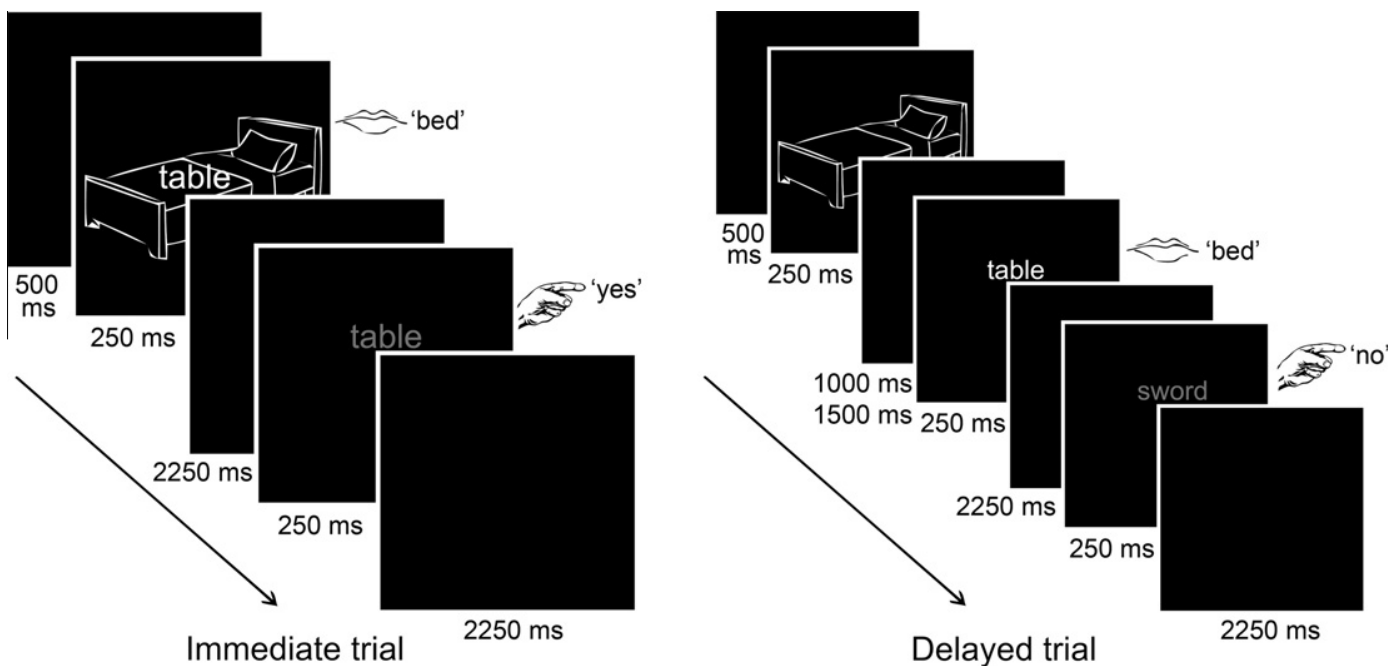

Fig. 2. Example of the structure of an immediate trial and a delayed trial of Experiment 1 . The verification word was always yellow in the experiment, whereas here it is exemplified in grey. The mouth indicates the vocal response; the finger indicates the manual response.

For the two delayed naming conditions (ISIs $1000 \mathrm{~ms}$ and $1500 \mathrm{~ms}$ ), there was no main effect of ISI, no main effect of distractor type, and no interaction between distractor type and ISI, all Fs $<1$. Therefore, the ISIs of $1000 \mathrm{~ms}$ and $1500 \mathrm{~ms}$ were collapsed in subsequent analyses of the delayed condition. Moreover, response mode sequence, i.e. whether participants started with immediate or delayed naming, did not reach significance in any analysis nor did it enter in any interactions, all $p s>.1$. Therefore, we collapsed the data from the two different sequences.

Pictures were named faster in the delayed than in the immediate condition, $F_{1}(1,17)=201.62, \quad M S E=10381$, $p<.001, F_{2}(1,31)=710.8, M S E=5214, p<.001$. Pictures in the semantically related condition were named more slowly than in the unrelated condition, $F_{1}(1,17)=11.42$, $M S E=493, p=.004, F_{2}(1,31)=8.86, M S E=1317, p=.006$, $\min F^{\prime}(1,47)=4.99, p=.03$. More importantly, a significant interaction between response mode and distractor type was found, $F_{1}(1,17)=10.61, \quad M S E=633, \quad p=.005$, $F_{2}(1,31)=13.76, M S E=1115, p<.001$. Simple effect analyses showed that the semantic interference effect was present for immediate naming, $F_{1}(1,17)=27.07, M S E=456$,

\section{Table 1}

Mean response time $(M)$, percent error $(P E)$, and mean ex-Gaussian parameter estimates $(\mu, \sigma, \tau)$ as a function of response mode and distractor type in Experiment 1.

\begin{tabular}{lrrrrr}
\hline Response mode/distractor type & $M$ & $P E$ & $\mu$ & \multicolumn{1}{l}{$\sigma$} \\
\hline Immediate & & & & & \\
Related & 895 & 9.0 & 720 & 69 & 176 \\
Unrelated & 856 & 7.9 & 699 & 57 & 161 \\
Difference & 39 & 2.1 & 21 & 12 & 15 \\
& & & & & \\
Delayed & & & & & \\
Related & 535 & 6.9 & 393 & 70 & 144 \\
Unrelated & 538 & 6.2 & 384 & 71 & 155 \\
Difference & -3 & 0.7 & 9 & -1 & -11 \\
\hline
\end{tabular}

Note. Mean response times and ex-Gaussian parameter estimates are given in milliseconds. $p<.001,95 \%$ CI $[22,52], F_{2}(1,31)=17.36, M S E=1548$ $p<.001,95 \%$ CI $[20.9,61.1], \operatorname{minF}^{\prime}(1,48)=10.58, p=.002$; but not for delayed naming, $F_{1}(1,17)<1,95 \% \mathrm{CI}[-19.8$, $16.6], F_{2}(1,31)<1,95 \% \mathrm{CI}[-18,12.4]$.

\section{Error percentages for naming}

Table 1 shows the mean error percentages for the immediate condition and the collapsed delayed condition. Logistic regression analyses of the error percentages revealed that the odds of a correct answer in delayed naming were 1.99 times higher than in immediate naming, $\beta$ coefficient $=0.69, S E=0.22$, Wald $Z=3.19, p=.001$. Distractor type was not a significant predictor in the model, nor was the interaction, $p s>.4$.

\section{Verification RTs}

In immediate naming, the mean RTs for the correct button-press responses were $653 \mathrm{~ms}$ in the semantically related and $640 \mathrm{~ms}$ in the unrelated condition. In delayed naming, the means were $687 \mathrm{~ms}$ in the semantically related and $686 \mathrm{~ms}$ in the unrelated condition. The verification RTs were overall $40 \mathrm{~ms}$ slower in the delayed condition than in the immediate condition, $F_{1}(1,17)=6.7$, $M S E=4679, \quad p=.019, \quad F_{2}(1,31)=34.76, \quad M S E=2008$, $p<.001$. No interactions were found between distractor type and response mode, both $F s<1$.

\section{Error percentages for verification}

For immediate naming, the mean error percentages for verification responses were 39.5 in the semantically related and 38.5 in the unrelated condition. For delayed naming, the percentages were 2.0 in both conditions. The odds of a correct verification in delayed naming are 27.4 times higher than in immediate naming, $\beta$ coefficient $=3.32$, $S E=0.22$, Wald $Z=15.33, p<.001$. Distractor type was not a significant predictor in the model, nor was the interaction, $p s>.9$. 
Distributional analyses of naming RTs

Fig. 3 gives the Vincentized cumulative distribution curves per response mode and distractor type. The figure shows that the semantically related condition was slower than the unrelated condition throughout the latency range in immediate naming, whereas the distractor conditions did not differ from each other regardless of naming latency in delayed naming. Thus, the semantic interference observed in the mean RTs in immediate naming is the result of a shift of the complete RT distribution towards responding more slowly in the related compared to the unrelated condition. Moreover, semantic interference in delayed naming is absent across the whole latency range.

Table 1 shows the means of the ex-Gaussian parameters $\mu, \sigma$ and $\tau$. Dependent $t$-tests revealed semantic interference in the $\mu$ parameter in immediate naming, $t(17)=-1.9, p=.037$, whereas in delayed naming the effect was absent, $p>.2$. All remaining $t$-tests were not significant, all ps $>1$. Thus, the ex-Gaussian analyses confirm the conclusion from the Vincentile analyses: The semantic interference in immediate naming is the result of distributional shifting, whereas delayed naming yields no semantic effect across the whole latency distribution.

\section{Post-hoc frequency analysis}

Although the frequency of the pictures' names was not an independent variable manipulated in the design of the experiment, post-hoc frequency analyses were conducted by acquiring frequency counts from CELEX (Baayen, Piepenbrock, \& van Rijn, 1993) for the pictures' names used in the experiment. Not all pictures' names in our materials could be analysed because the range of frequencies for the high and low conditions obtained with the median split were not discrete enough. Therefore, a new cut-off was established, with 11 items per condition (range low-frequency condition: 4.9-22.8 per million; range high-frequency condition: $81.8-303.2$ per million).

Pictures in the high-frequency condition were named overall $22 \mathrm{~ms}$ faster than in the low-frequency condition, $F_{1}(1,17)=9.56, \quad M S E=1751, p=.006, \quad F_{2}(1,21)<1$. The interaction with response mode was also significant, $F_{1}(1,17)=7.21, \quad M S E=2304, \quad p=.016, \quad F_{2}(1,21)=1.51$, $M S E=5058, p=.233$. Planned comparisons showed that the frequency effect was only reliable in immediate naming: Pictures in the high-frequency condition were named $48 \mathrm{~ms}$ faster than pictures in the low-frequency condition, $F_{1}(1,17)=12.47, M S E=2655, p=.002$; whereas in delayed naming, pictures in the low-frequency condition were named $4 \mathrm{~ms}$ faster, $F_{1}<1$. The interactions with distractor type were not significant, $F_{1}<1$.

\section{Discussion}

In Experiment 1, we tested for the presence of a semantic effect in both immediate and delayed naming with the standard PWI paradigm. Contrary to Janssen et al. (2008) and similar to Mädebach et al. (in press), we failed to replicate the semantic interference effect in delayed naming whereas we obtained a sizeable semantic interference effect in immediate naming with our materials. Moreover, we tested post-hoc for a frequency effect, which was found only in immediate but not in delayed naming, suggesting that participants prepared their responses in delayed naming. The fact that the frequency effect was not significant in the by-item analysis is probably because our materials were not selected on the basis of their frequency but on the basis of semantic categories instead. The lack of frequency and semantic effects in delayed naming corroborates the hypothesis that the picture name was prepared at picture presentation and retained from articulation until the presentation of the cue.

The RT distributional analyses corroborated the findings of the mean RT analyses. A shift in the entire latency distribution was found as a function of distractor type only in immediate naming. Moreover, semantic interference was reflected in the $\mu$ parameter of the ex-Gaussian function for immediate naming, but not for delayed naming.

To address the concern that the distractor word was not relevant for the task at hand in the delayed condition, we used a verification task. Participants were much more

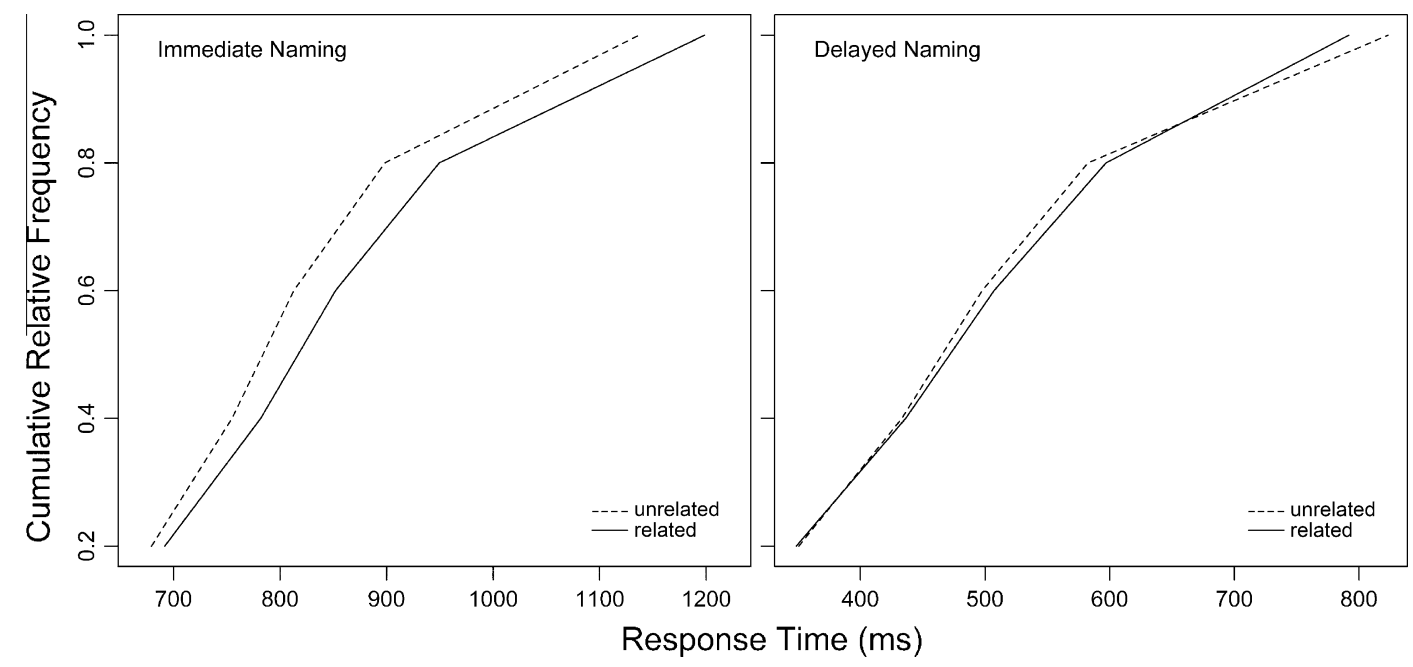

Fig. 3. Vincentized cumulative distribution curves for the related and unrelated conditions in immediate naming (left panel) and delayed naming (right panel) of Experiment 1. 
accurate in the verification task in the delayed condition than in the immediate condition. The high error rate in immediate naming suggests that planning the picture name goes at the expense of not attending enough to the distractor in order to perform the verification task. However, the semantic interference effect in immediate naming was independent of accuracy in the verification task, indicating the robustness of the effect.

The time parameters used in this experiment are somewhat different from the ones in Janssen et al. By restricting the presentation of the picture, we could better control participants' lexical access in delayed naming. Although it is unlikely that the difference in these parameters is the cause of the discrepancy in the results, we cannot rule out this possibility at this point. Experiments 2 and 3, however, address this concern more directly. The findings of Experiment 1 show that, without task decision, semantic interference is obtained in immediate naming but not in delayed naming. These findings are in accordance with the competition hypothesis, but go against the predictions of the response exclusion account.

\section{Experiment 2}

In the second experiment, we introduced task decisions and tested for the semantic interference effect in both immediate and delayed naming and reading using the design and materials of Janssen et al. (2008) translated into Dutch. Note that, contrary to Janssen et al., our participants performed both delayed and immediate tasks and we recorded and analysed the word reading RTs as well (Janssen et al. only reported picture naming RTs). We analysed reading RTs for the following reason. According to the response exclusion hypothesis, semantic interference should be obtained not only in naming but also in reading in the delayed condition because the task-irrelevant response needs to be removed from the response buffer in both cases. Upon presentation of the picture, the response to the picture will be buffered. In a word reading trial, this response needs to be excluded from the buffer in order for it to accommodate the response to the distractor. If the two responses share response relevant criteria such as their semantic category, a semantic interference effect should be found for word reading. In contrast, according to the competition hypothesis, semantic interference should always be absent in both immediate and delayed reading because words can be read aloud via a shallower route that does not require access to lemma information (Roelofs, 1992, 2003). In particular, words can be read by mapping orthographic lexical forms onto phonological lexical forms or by applying grapheme-to-phoneme conversion rules (cf. Coltheart, Rastle, Perry, Langdon, \& Ziegler, 2001).

According to our task-decision account, in case of task decisions, semantic interference should be present or absent in immediate naming depending on the relative average speed of picture naming and task-decision processes. According to the competition hypothesis, if participants prepare the picture name at picture presentation, no semantic interference should be found in delayed naming. The presence or absence of semantic interference should hold not only for the mean RTs but also for the whole RT distributions. According to the response exclusion hypothesis, however, semantic interference should always be found in both delayed and immediate naming and in reading in the delayed condition.

\section{Method}

\section{Participants}

Twenty-eight students ( 5 male) from the participant pool of Radboud University Nijmegen participated in the experiment for compensation of 5 Euros. All participants fulfilled the same criteria as for Experiment 1.

\section{Materials and design}

The same 40 pictured objects as in Janssen et al. (2008) were used. Our pictures were taken from Snodgrass and Vanderwart's (1980) database or from our own database. The pictures were white line drawings on a black background, scaled to fit into a frame of $10 \mathrm{~cm} \times 10 \mathrm{~cm}$. Basic-level names in Dutch were determined, which coincided with the direct Dutch translation from Janssen et al.'s pictures' names, except for the item "lips" (changed into the Dutch word mond 'mouth'). A list of the materials can be found in Appendix B. The 40 pictures were combined with 40 semantically related distractor words, which were the Dutch translations of Janssen et al.'s distractors (except for the word "cards", translated into the singular form, the word "kidney", translated into lever 'liver', and the word "flask", translated into thermos). For the semantically unrelated condition, we used the same semantically unrelated pairs as Janssen et al., with their respective Dutch translations. The words were presented in font Arial size 36. Each experimental list contained the 80 picture-distractor pairs, which were presented once in the naming condition and once in the reading condition, yielding 160 trials per response mode. The items were randomised using Mix (Van Casteren \& Davis, 2006) following the same constraints on the randomisation as in Experiment 1, with the addition of one constraint: The same task did not occur in more than three consecutive trials. There was one unique randomization per participant per response mode. Participants took part in both the immediate and the delayed conditions and the order of response mode blocks was counterbalanced across participants.

\section{Procedure and apparatus}

The apparatus and the set up were identical to Experiment 1. Participants were instructed to either name the picture (green distractor, RGB: $0,160,0$ ) or to read the distractor out loud (blue distractor, RGB: 0,0,200) depending on the colour of the distractor. Moreover, specific instructions were given for each response mode condition. Next, participants were given a booklet to get familiarised with the pictures and the names to be used in the experiment. A naming training phase followed in which the 40 pictures used in the experiment were presented once in the centre of the screen with their respective names $3 \mathrm{~cm}$ below the picture. Participants were instructed to read aloud the names of the pictures. Before the start of each block, a practice session was administered. The trial structure of the practice phase was identical to the trial structure of the experimental block that would be administered next. 
Four pictures from four different categories, none of which were used as experimental stimuli, were selected for the practice sessions. The four pictures were combined with a semantically related and an unrelated distractor, totalling eight trials, half of which were naming trials and half of which reading trials, presented in random order.

The trial structures were similar to Janssen et al. (2008). A trial of the immediate condition started with the presentation of the picture-distractor pair for $500 \mathrm{~ms}$. A black screen followed for $2000 \mathrm{~ms}$. In the delayed condition, a trial started with the presentation of the picture for $1000 \mathrm{~ms}$ followed by the superposition of the distractor word. The picture and the distractor remained together on the screen for $500 \mathrm{~ms}$. A black screen followed for $2000 \mathrm{~ms}$. An example of the trial structures can be found in Fig. 4. The whole experimental session lasted approximately $25 \mathrm{~min}$. The registration of the vocal responses started as soon as the distractor word was displayed on the screen and lasted $2500 \mathrm{~ms}$. The target pictures and the distractors always appeared in the centre of the screen.

\section{Analysis}

Both picture naming trials and word reading trials were analysed in the same way as in Experiment 1 (except for the verification task, which was not part of Experiment 2 ). The response mode sequence was treated as a between-subjects and within-items variable and task (reading/naming), response mode and distractor type as within-subjects and within-items.

\section{Results}

\section{Mean naming and reading $R T S$}

Table 2 shows the means of the naming and reading RTs for the immediate and the delayed conditions. Response mode sequence did not enter in any interactions; therefore, we collapsed the data from the two sequences. Participants were $114 \mathrm{~ms}$ faster in the delayed block than in the immediate block, $\quad F_{1}(1,27)=27.72, \quad M S E=26129, \quad p<.001$, $F_{2}(1,39)=656.1, M S E=3337, p<.001$. Overall naming was
$123 \mathrm{~ms}$ slower than overall reading, $F_{1}(1,27)=152.8$, $M S E=5597, \quad p<.001, \quad F_{2}(1,39)=333.35, \quad M S E=7445$, $p<.001$. Task and response mode interacted, $F_{1}(1,27)=$ 44.56, $M S E=7759, p<.001, F_{2}(1,39)=165.1, M S E=6292$, $p<.001$. Reading was significantly faster than naming in both the immediate block, $F_{1}(1,27)=195.34, M S E=5857$, $p<.001, F_{2}(1,39)=320.66, M S E=10498, p<.001$; and in the delayed block, $F_{1}(1,27)=7.56, M S E=7499, p=.01$, $F_{2}(1,39)=47.733, M S E=3239, p<.001$. The distractor type effect did not reach significance as a main effect, $F_{1}(1,27)<1,95 \%$ CI $[-5.7,9.2], F_{2}(1,39)<1,95 \%$ CI $[-6.3$, 11.7]; nor entered in significant interactions, all ps $>.1$.

\section{Error percentages for naming and reading}

For the error percentages, shown in Table 2, no predictor was significant in the logistic-regression model, all ps > .1.

\section{Distributional analyses of naming and reading $R T S$}

RT distribution analyses confirmed the absence of a semantic effect for both reading and naming in delayed and immediate conditions. Fig. 5 gives the Vincentized cumulative distribution curves for naming and reading per response mode. The figure shows that the RT curves for the two distractor types are completely overlapping for both immediate and delayed naming and reading in the immediate condition, and nearly overlapping for reading in the delayed condition.

Table 2 shows the means of the ex-Gaussian parameters $\mu, \sigma$ and $\tau$. Dependent $t$-tests revealed no significant effects for any of the parameters, all ps $>$.2. Thus, the ex-Gaussian analyses confirmed the absence of semantic effects in naming and reading, as already suggested by the Vincentile analyses.

\section{Post-hoc frequency analysis}

Post-hoc frequency analyses were conducted in the same way as for Experiment 1 . Only 26 names were included in the analyses in order to have a clear separation of frequency ranges (range low-frequency condition: 1.58.8 per million; range high-frequency condition: 81.8-

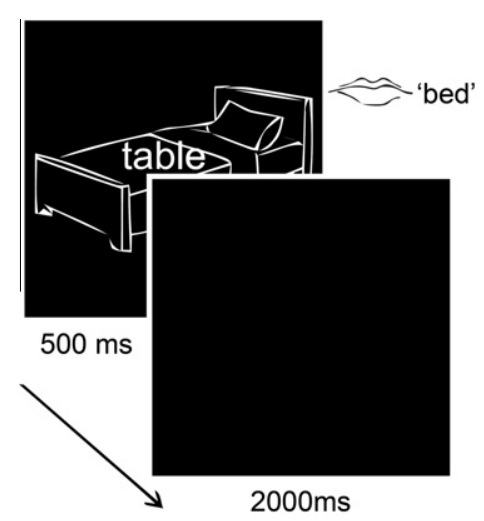

Immediate trial

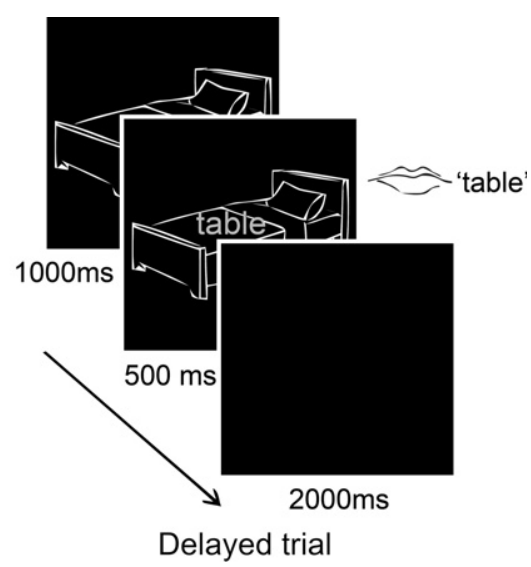

Fig. 4. Example of the structure of a delayed and an immediate trial in Experiment 2. The distractor words were green or blue in the experiment. Here, for exemplification, grey distractors indicate the reading trials (blue in the experiment) and white distractors indicate the naming trials (green in the experiment). 
Table 2

Mean response time $(M)$, percent error $(P E)$, and mean ex-Gaussian parameter estimates $(\mu, \sigma, \tau)$ as a function of task, response mode, and distractor type in Experiment 2.

\begin{tabular}{|c|c|c|c|c|c|}
\hline Task/response mode/distractor type & $M$ & $P E$ & $\mu$ & $\sigma$ & $\tau$ \\
\hline \multicolumn{6}{|l|}{ Naming } \\
\hline \multicolumn{6}{|l|}{ Immediate } \\
\hline Related & 925 & 4.8 & 746 & 67 & 179 \\
\hline Unrelated & 915 & 3.9 & 742 & 72 & 175 \\
\hline Difference & 10 & 0.9 & 4 & -5 & 4 \\
\hline \multicolumn{6}{|l|}{ Delayed } \\
\hline Related & 730 & 3.0 & 580 & 83 & 152 \\
\hline Unrelated & 723 & 3.4 & 579 & 82 & 146 \\
\hline Difference & 7 & -0.6 & 1 & 1 & 6 \\
\hline \multicolumn{6}{|l|}{ Reading } \\
\hline \multicolumn{6}{|l|}{ Immediate } \\
\hline Related & 719 & 2.7 & 582 & 70 & 137 \\
\hline Unrelated & 717 & 2.4 & 581 & 67 & 137 \\
\hline Difference & 2 & 0.3 & 1 & & 0 \\
\hline \multicolumn{6}{|l|}{ Delayed } \\
\hline Related & 678 & 2.4 & 554 & 52 & 125 \\
\hline Unrelated & 687 & 3.2 & 571 & 61 & 118 \\
\hline Difference & -9 & -0.8 & -17 & -9 & 7 \\
\hline
\end{tabular}

Note. Mean response times and ex-Gaussian parameter estimates are given in milliseconds.

1037.5 per million). A main effect of frequency was found, with pictures in the high-frequency condition being named overall $37 \mathrm{~ms}$ faster than in the low-frequency condition, $F_{1}(1,27)=22.34, M S E=3740, p<.001, F_{2}(1,24)=7.62$, $M S E=5168, p=.011$. The interaction with distractor type was not significant, $F s<1$.The interaction with response mode was significant, $F_{1}(1,27)=8.34, M S E=3259, p=$ $.008, F_{2}(1,24)=5.4, M S E=3190, p=.029$. Planned comparisons showed that, in immediate naming, pictures with high-frequency names were named $60 \mathrm{~ms}$ faster than pictures with low-frequency names, $F_{1}(1,27)=22.47$, $M S E=4603, \quad p<.001, \quad F_{2}(1,24)=8.14, \quad M S E=6681$, $p=.009$; whereas in delayed naming, a non-significant difference of $15 \mathrm{~ms}$ was found, $p>.09$.

\section{Discussion}

The results of Experiment 2 show that word reading was performed faster than picture naming, which is in accordance with the idea that words can be read aloud via a shallower route than pictures can be named (see, e.g., Roelofs, 1992, 2003). The semantic interference effect, however, was absent not only in delayed naming but also in immediate naming, an observation also made by Mädebach and colleagues (in press). Semantic interference was also absent in reading, contrary to the prediction derived from the response exclusion. Complementary to the mean RT analyses, Vincentizing and ex-Gaussian analyses confirmed the absence of semantic interference throughout the RT distributions. Post-hoc frequency analyses indicated that pictures in the high-frequency condition were named faster than pictures in the low-frequency condition in immediate naming only, replicating the well-known frequency effect (Oldfield \& Wingfield, 1965) also found by Janssen et al. (2008). This suggests that participants generally prepared the picture name at picture presentation.
Experiments 1 and 2 failed to show any semantic interference in delayed naming, either with or without task decisions. A failure to replicate, however, is more credible with more experiments supporting it. Therefore, in Experiment 3 , only the delayed condition was tested.

\section{Experiment 3}

Although we did not find a frequency effect in delayed naming in the post-hoc analysis in Experiment 2, we cannot be entirely certain that our participants prepared the picture name on the same number of trials as the participants of Janssen et al. (2008) presumably did. To address this concern, we increased the proportion of naming trials from 50\% (as in previous studies and in Experiments 1 and 2 ) to $75 \%$. Half of the participants had to name the pictures in $75 \%$ of the trials and read the distractors aloud in only $25 \%$ of the trials. The other half of the participants had the reverse proportion. If participants have to mostly name the picture throughout the experiment (i.e., the 75\% naming condition), they are really invited to prepare the picture name on each trial. This should yield the semantic interference effect predicted by the response exclusion hypothesis. The reverse proportion (25\% naming, 75\% reading) was used to assess the effectiveness of the proportion manipulation. If the proportion manipulation is effective, naming RTs should be shorter for the $75 \%$ than for the $25 \%$ condition. We used the same materials as for Experiment 1 because this set of materials yielded a considerable semantic interference effect in immediate naming in that experiment. According to the competition hypothesis, semantic interference should be found neither in naming nor in reading. According to the response exclusion account, on the contrary, semantic interference should be found for both reading and naming, especially in the $75 \%$ naming condition. 

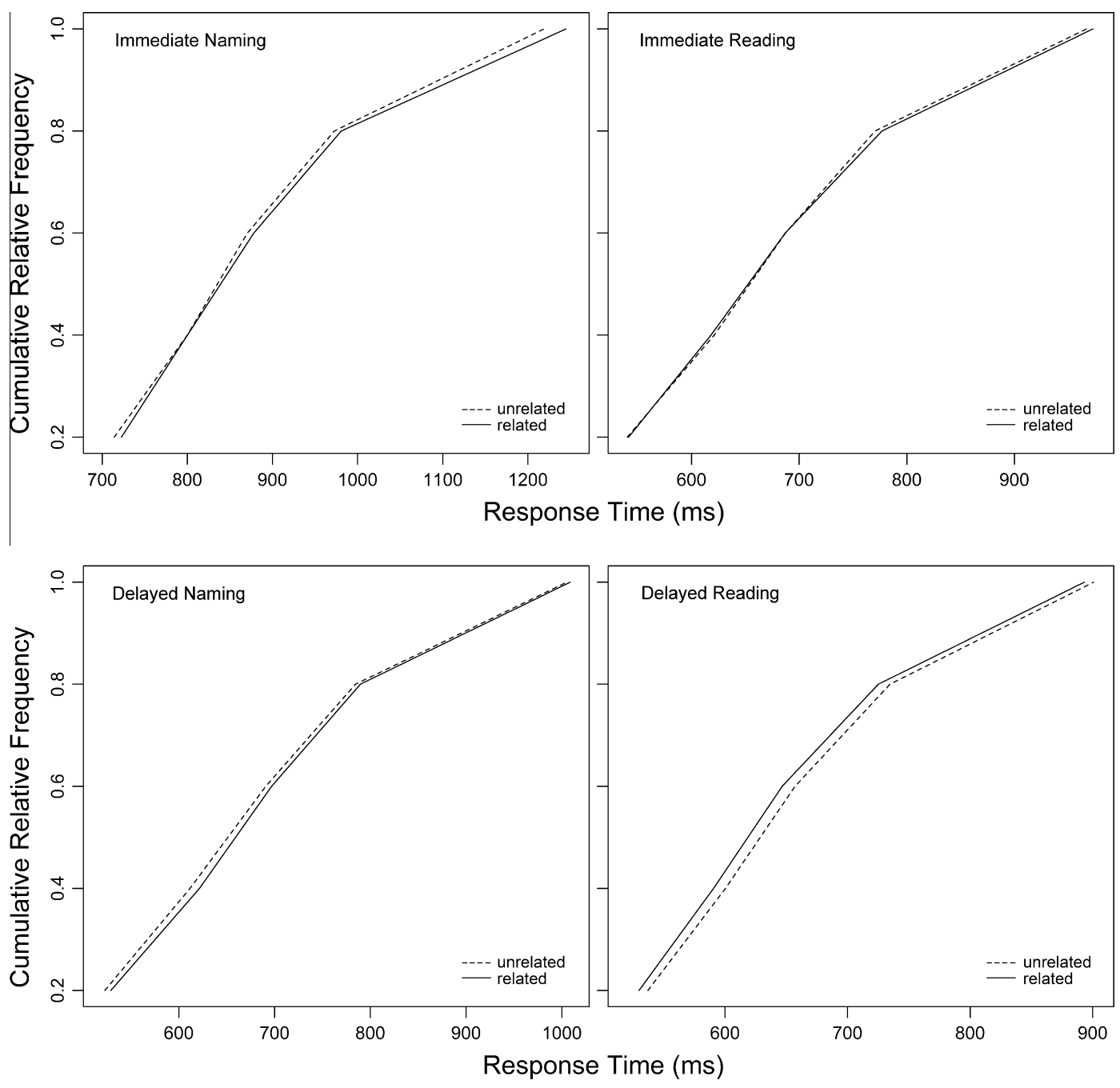

Fig. 5. Vincentized cumulative distribution curves for the related and unrelated conditions in immediate reading (top left panel), immediate naming (top right panel), delayed reading (bottom left panel) and delayed naming (bottom right panel) of Experiment 2.

\section{Method}

\section{Participants}

Twenty-eight students ( 9 male) from the participant pool of Radboud University Nijmegen participated in the experiment for compensation of 5 Euros. All participants fulfilled the same criteria as for Experiments 1 and 2 .

\section{Materials and design}

The same 64 picture-distractor word pairs from Experiment 1 were used. The colours used for the reading and naming trials were identical to Experiment 2. The proportion manipulation was used as a between-subject factor. In the $75 \%$ naming-25\% reading condition, the 64 picture-distractor pairs were repeated once with the distractors coloured blue and three times with the distractors coloured green. In this way, $75 \%$ of the experimental list consisted of picture naming trials and only $25 \%$ of the trials were word reading trials. In the $25 \%$ naming- $75 \%$ reading condi- tion, the reversed proportion was used. Each experimental list contained 256 items, which were randomised using Mix (Van Casteren \& Davis, 2006). The same constraints on the randomisation as in Experiment 2 were used. There was one unique randomization per participant. Fourteen participants took part in the $75 \%$ naming-25\% reading condition and the other 14 participants took part in the $25 \%$ naming-75\% reading condition. All participants performed only the delayed-response task.

\section{Procedure and apparatus}

The apparatus and the set up were equal to Experiments 1 and 2 . Before the experiment, participants were familiarised with the pictures and the words used in the experiment. They were instructed to either name the picture or to read the word out loud depending on the colour of the word. Moreover, specific instructions were given to participants depending on the proportion condition they were assigned to in order to already bias them towards a 
"picture naming" or a "word reading" mode. For example, participants in the $25 \%$ naming-75\% reading condition were told that they would have to read the word most of the time. A block of 32 practice trials preceded the experiment proper with the experimental pictures presented once with a semantically unrelated distractor not used in the experiment. The proportion manipulation was also built into the practice session. The trial structure was the same as for the delayed trials of Experiment 2.

\section{Analysis}

Both picture naming trials and word reading trials were analysed in the same way as for Experiment 2. The proportion manipulation was treated as a between-subjects and within-items variable, and task (reading/naming) and distractor type as within-subjects and within-items variables.

\section{Results}

\section{Mean naming and reading $R T S$}

Table 3 shows the means of the naming and reading RTs for both proportion manipulations. In the 75\% naming-25\% reading condition, participants were on overage $109 \mathrm{~ms}$ faster than participants in the other condition, $F_{1}(1,26)=11.08, M S E=44614, p=.003, F_{2}(1,31)=725.4$, $M S E=1584.50, p<.001$. Overall naming was $20 \mathrm{~ms}$ faster than overall reading, $F_{1}(1,26)=19.62, M S E=3343.41$, $p<.001, F_{2}(1,62)=88.23, M S E=1681.57, p<001$. More importantly, however, naming RTs were smaller in the $75 \%$ than in the $25 \%$ condition [task by proportion interaction, $F_{1}(1,26)=67.89$, MSE $=1672.13, p<.001 ; F_{2}(1,31)=$ $65.6, M S E=2262, p<.001]$, showing that participants prepared their naming responses according to the proportion condition they were assigned to. A main effect of distractor type was, however, absent, $F_{1}(1,26)<1,95 \%$ CI $[-8.58$,

\section{Table 3}

Mean response time $(M)$, percent error $(P E)$, and mean ex-Gaussian parameter estimates $(\mu, \sigma, \tau)$ as a function of task, proportion manipulation, and distractor type in Experiment 3.

\begin{tabular}{|c|c|c|c|c|c|}
\hline $\begin{array}{l}\text { Task/proportion/manipulation/ } \\
\text { distractor type }\end{array}$ & $M$ & $P E$ & $\mu$ & $\sigma$ & $\tau$ \\
\hline \multicolumn{6}{|l|}{ Naming } \\
\hline \multicolumn{6}{|l|}{$75 \%$ naming } \\
\hline Related & 556 & 3.1 & 430 & 53 & 127 \\
\hline Unrelated & 564 & 2.6 & 435 & 63 & 129 \\
\hline Difference & -8 & 0.5 & -5 & -10 & -2 \\
\hline \multicolumn{6}{|l|}{$25 \%$ naming } \\
\hline Related & 787 & 6.2 & 634 & 69 & 150 \\
\hline Unrelated & 783 & 5.6 & 649 & 92 & 134 \\
\hline Difference & 4 & 0.6 & -15 & -23 & 16 \\
\hline \multicolumn{6}{|l|}{ Reading } \\
\hline \multicolumn{6}{|l|}{$25 \%$ reading } \\
\hline Related & 596 & 2.0 & 510 & 43 & 86 \\
\hline Unrelated & 609 & 4.5 & 508 & 39 & 100 \\
\hline Difference & -13 & -2.5 & 2 & 4 & -14 \\
\hline \multicolumn{6}{|l|}{$75 \%$ reading } \\
\hline Related & 650 & 2.7 & 539 & 53 & 111 \\
\hline Unrelated & 641 & 3.2 & 535 & 43 & 106 \\
\hline Difference & 9 & -0.5 & 4 & 10 & 5 \\
\hline
\end{tabular}

Note. Mean response times and ex-Gaussian parameter estimates are given in milliseconds.
7.10], $F_{2}(1,31)<1,95 \% \mathrm{CI}[-25.2,21.1]$, and so were the interactions, $p s>.1$.

\section{Error percentages for naming and reading}

Table 3 shows error percentages for the naming and reading $\mathrm{RTs}$ for both proportion manipulations. For the error percentages, only task was a significant predictor in the model, $\quad \beta$ coefficient $=-1.19, S E=0.334$, Wald $Z=3.57$, $p<.001$ : The odds of a correct response in reading are 3.29 times higher than in naming.

\section{Distributional analyses of naming and reading $R T S$}

RT distribution analyses confirmed the absence of a semantic effect. Fig. 6 gives the Vincentized cumulative distribution curves for naming and reading per distractor condition and proportion manipulation. For naming, the RT curves for the two distractor conditions are completely overlapping, confirming the absence of a semantic effect across Vincentiles. For the reading task, small effects seem to be present in the tail of the distribution. The effect tends to be one of semantic interference in the $25 \%$-reading condition and facilitation in the $75 \%$-reading condition.

Table 3 shows the means of the ex-Gaussian parameters, $\mu, \sigma$, and $\tau$. Dependent $t$-tests revealed no significant differences for any of the parameters, all $p s>.1$. Thus, the ex-Gaussian analyses confirm the absence of a semantic effect in naming and in reading, as already suggested by the Vincentile analyses.

\section{Discussion}

In this experiment, we observed that naming and reading RTs varied as a function of the proportion manipulation, such that performance was faster for the task participants had to execute most of the time. Independently of this sensitivity, however, the semantic interference effect remained absent in both naming and reading and throughout the RT distributions. The absence of semantic interference in delayed naming corresponds to the findings of Experiments 1 and 2 and to what Mädebach et al. (in press) observed, and differs from what Janssen et al. (2008) obtained. Moreover, the absence of semantic interference in delayed reading goes against the predictions of the response exclusion hypothesis.

\section{General discussion}

Disagreement exists about whether lexical selection in word production is a competitive process. Lexical competition models predict semantic interference from distractor words in immediate but not in delayed picture naming. In contrast, Janssen et al. (2008) obtained semantic interference in delayed naming when participants had to decide between naming the picture or reading the distractor word aloud depending on its ink colour. However, Mädebach et al. (in press) obtained no semantic interference in delayed naming, even though the effect was present in a standard immediate-naming experiment for another group of participants. Moreover, Mädebach et al. failed to obtain semantic interference in immediate naming using the task- 

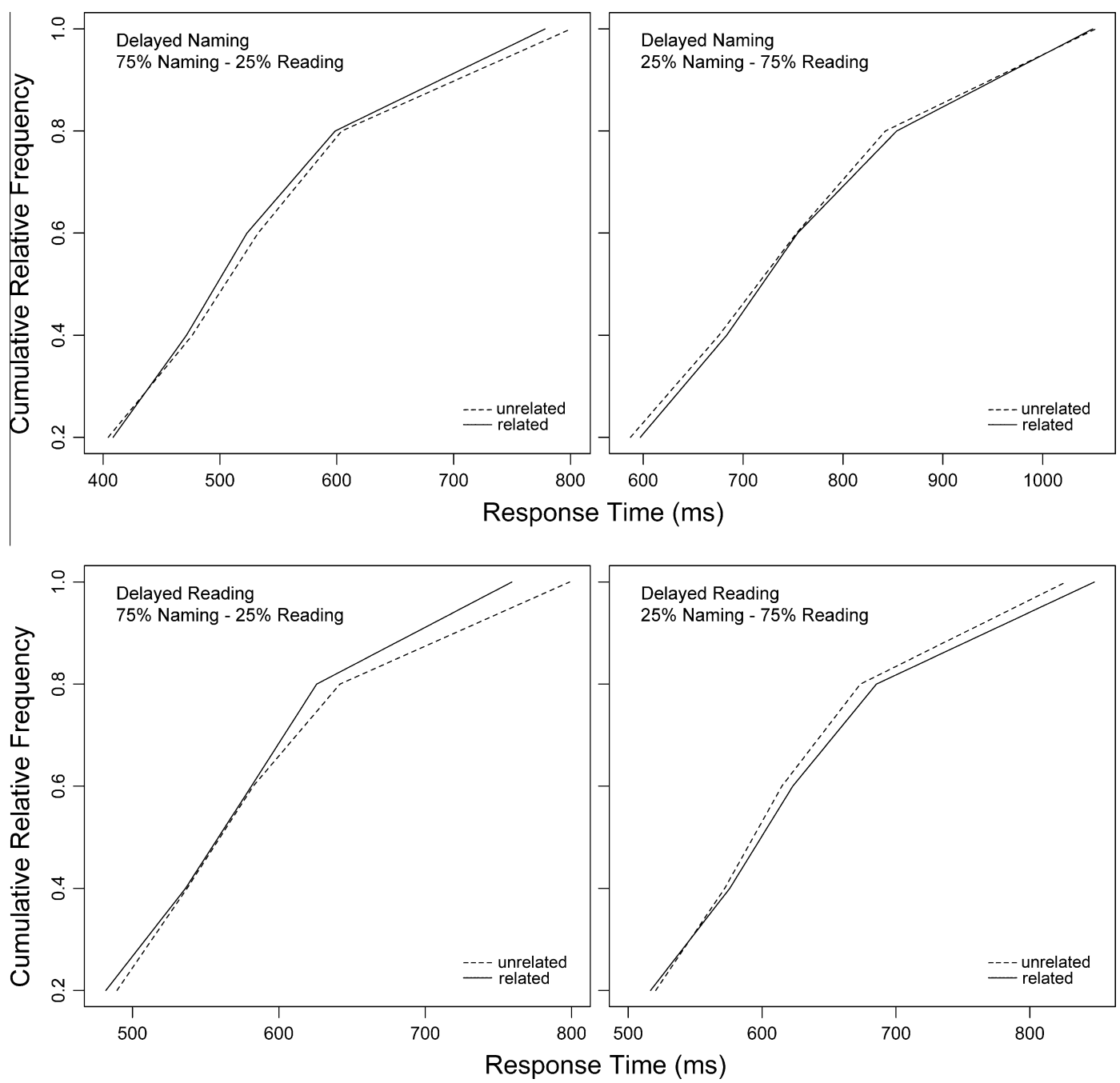

Fig. 6. Vincentized cumulative distribution curves for the related and unrelated conditions in delayed naming (top left panel) and delayed reading (bottom left panel) for the $75 \%$ naming-25\% reading condition, and in delayed naming (top right panel) and delayed reading (bottom right panel) for the $25 \%$ naming-75\% reading condition of Experiment 3.

decision procedure of Janssen et al. In the present article, we raised two issues that might be of concern: task decision in immediate picture-naming and the semantic interference effect in delayed picture naming. Regarding the former, we presented a task-decision account which holds that semantic interference from lexical competition may be hidden depending on the relative speed of task-decision and picture-word processes. Our first two experiments examined the merits of this account. Concerning our second aim, we tested for semantic interference in delayed picture naming in all three experiments, in an attempt to replicate Janssen et al.'s findings. We performed RT distributional analyses in all three experiments.

In Experiment 1, task decisions did not play a role as participants only named pictures whereas the distractor words were never read aloud. Given that there is no task decision in this experiment, the competition hypothesis predicts semantic interference in immediate but not in delayed naming. In contrast, according to the response exclu- sion account, semantic interference should be obtained in both immediate and delayed naming. We obtained semantic interference in immediate but not in delayed naming. These observations held for both mean RTs and RT distribution components. These results support the lexical competition account of semantic interference and challenge the response exclusion account.

The inclusion of a verification task at the end of each trial of Experiment 1 could have influenced the results of this experiment by affecting participants' performance in the task. However, the size of the semantic interference effect found for immediate naming is very similar to interference effects previously found using a comparable set of materials without the verification task (Roelofs, 2006, Experiment 1B; Roelofs, 2007, Experiment 1). Moreover, Experiments 2 and 3 tested delayed naming without the verification task and replicated the findings of Experiment 1 for delayed naming. So although the verification task might have affected performance in picture 
naming in general, it does not seem to have affected the results obtained.

In Experiment 2, we introduced task decisions and we tested for semantic interference in both immediate and delayed naming and reading using the design and materials of Janssen et al. (2008) translated into Dutch. The response exclusion hypothesis predicts semantic interference in both immediate and delayed naming and in reading in the delayed condition. The competition hypothesis, however, predicts that competition will play a role in lexical selection only in immediate naming but never in delayed naming. According to our task-decision account, semantic interference from lexical competition in immediate naming may be hidden depending on the relative speed of task-decision and picture-naming processes, which may create cognitive slack, absorbing semantic interference from competition. We obtained no semantic interference for both immediate and delayed naming. Moreover, according to the competition hypothesis and contrary to the response exclusion hypothesis, we did not find semantic interference in reading.

In Experiment 3, we made a further attempt to replicate Janssen et al. Since we did not manipulate frequency directly in Experiments 1 and 2, we could not be certain that our participants were preparing the picture name as often as the participants did in the study of Janssen et al. So we manipulated the proportion of naming and reading trials. The idea was that if participants had to name the picture in the majority of the trials, they would be very likely to prepare the picture name as soon as possible. This should increase the chance that the experiment yields the semantic interference that is predicted by the response exclusion hypothesis. We observed that naming RTs varied as a function of trial proportions such that participants were always faster in naming in the $75 \%$ than in the $25 \%$ condition, attesting the effectiveness of the proportion manipulation. Semantic interference, however, was absent regardless of the proportion of naming and reading trials and across the whole RT distribution. Furthermore, no semantic interference was found in the reading RTs. These findings go against the predictions of the response exclusion hypothesis.

Taken together, the results of Experiments 1 and 2 support our account that task decisions may hide semantic interference from lexical competition depending on the relative speed of task-decision and picture-word processes. As we already noted, our task-decision account of the absence of semantic effects in immediate naming, if adopted by the response exclusion account, would result in very contradictory assumptions. Task decision can only hide semantic interference if the effect occurs within 200$300 \mathrm{~ms}$ after picture-word onset. However, the response exclusion account maintains that semantic interference arises after phonological encoding, which is assumed to be accomplished only around $500 \mathrm{~ms}$ after picture onset (cf. Indefrey \& Levelt, 2004; Roelofs, 2007). Moreover, a response can only be excluded after the task is known, which means that response exclusion can by no means take place in parallel with the task-decision process. Consequently, semantic interference arising from response exclusion cannot be absorbed into the slack created by the task-decision process.
Furthermore, we failed to find semantic interference in delayed naming in three experiments after manipulating the time parameters of stimulus presentation (Experiment 1 ), the presence or absence of task decisions (Experiments 1 and 2), and the proportion of naming and reading trials in the experiment (Experiment 3). Other features, such as the colours used in the experiments and the instructions given to participants, were already manipulated by Mädebach et al. (in press), but these authors also failed to induce semantic interference in delayed naming.

\section{Role of attention}

We assumed that participants suspend the planning of the picture name before word-form encoding because this stage has been shown to require attention (Reynolds \& Besner, 2006; Roelofs, 2008a). An alternative explanation for our findings that does not rely on the cognitive slack logic would be that paying attention to the colour of the distractor word to decide which task to perform reduces the effectiveness of that word as a semantic distractor. This explanation is unlikely, however, based on the following. Firstly, evidence from the colour-word Stroop task (Stroop, 1935 ) suggests that attending to the colour of a word helps the word to be processed (e.g., La Heij, Kaptein, Kalff, \& de Lange, 1995; Lamers \& Roelofs, 2007). Similarly, attention to an attribute of an object, such as its movement, facilitates processing of the moving object itself (O'Craven, Downing, \& Kanwisher, 1999). So it seems unlikely that participants are able to attend to the colour of the word only while preventing processing the word itself, thereby diminishing the word's effectiveness. So this alternative explanation cannot account for our findings as attending to the colour of the word would have, if anything, increased the effectiveness of the distractor word. Secondly, Mädebach et al. (in press) reported an experiment very similar to our Experiment 2; however, the task decision was a go/no-go decision: Depending on the colour of the word, participants named the picture or did not respond at all. They found semantic interference in immediate naming in this case, although the effect was smaller than what they obtained using the standard PWI. As the go/ no-go decision is presumably easier than the "name the picture/read the word" decision, these findings provide further support for the proposal that it is the cognitive slack in task decisions, rather than divided attention, that causes semantic interference in the RTs to diminish or even disappear.

Based on our account of relative speed of processing, one may hypothesise that relatively slow responses in immediate naming should show semantic interference because lexical selection presumably took longer than the task-decision process in these cases, and hence no slack was available to absorb the semantic effect. And indeed, for Experiment 2, a semantic interference effect of $25 \mathrm{~ms}$ seems to be present in the means of the fifth (i.e., slowest) quantile for immediate naming, although a $t$-test showed that this effect was not significant, $p>.2$. The prediction of semantic interference for the slowest responses is, however, not as straightforward as it may seem. It is difficult to 
pinpoint which processes caused longer RTs. It could be that RTs were long because lexical selection took relatively much time, exceeding task-decision duration and prolonging the RTs. If so, there would be no slack and the relatively long RTs should show semantic interference. However, it is equally plausible that the task decision took relatively long, thereby yielding long picture naming RTs. If so, there should be enough slack to absorb the semantic effect, which should then be absent in the relatively slow responses. Moreover, task-decision and lexical selection processes occur early in the chain of processes leading to articulation. The RTs not only reflect these early processes but also later processes, such as word-form encoding. A relatively long RT could also be the result of the duration of these later processes. Again, RTs would be relatively long, but slack would be present to absorb the semantic interference. In short, it is difficult to directly relate RTs to the duration of each of the different processes. The prediction of semantic interference for the slow responses would only hold if the long RTs are mainly caused by slow picture-naming processes up to lexical selection, but this is unlikely to be the case. This reinforces the idea that it is not the variable relative speed of each process that matters but the average relative speed of picture naming and task-decision processes. This is illustrated by the results of computer simulations, which we report next.

\section{Computer simulations of the effect of task decisions}

The experiments in the present study support our theoretical claim that task decisions may hide semantic effects from distractor words in picture naming. In this section, we demonstrate the utility of this theoretical account by means of computer simulations using the WEAVER++ model of attention and language performance (e.g., Roelofs, 2003, 2007, 2008a). This model has been applied to divided-attention situations, such as dual-task performance in PRP experiments (Roelofs, 2008a). Besner and Care (2003) pointed out the similarity between task-choice and PRP experiments: Task decisions as well as actual responding in PRP experiments may create cognitive slack, which can hide effects in concurrent tasks. Along the same line, Dell'Acqua et al. (2007) argued that cognitive slack in PRP experiments may absorb semantic interference. Below, we demonstrate that our theoretical account not only explains the effect of task decisions in the present experiments but also the findings of Dell'Acqua et al. (2007) using the PRP procedure. Moreover, the simulations demonstrate that cognitive slack may hide semantic effects even if lexical selection latencies are variable.

The computational protocol was the same as in previous WEAVER++ simulations of picture naming in the PWI paradigm (i.e., Roelofs, 1992, 2003, 2006, 2008a, 2008b). The parameter values were fixed and identical to those in earlier simulations except that the selection threshold was set at 3.0. In the simulations of the effect of task decision in the present experiments, we assumed a task-decision delay of $200 \mathrm{~ms}$ after colour perception. These parameter values were informally chosen to optimise the fit between model and data.

The left-hand panel of Fig. 7 shows the simulation results. Without task decision, a full-blown semantic interference effect occurs in the model, as typically observed with immediate naming in picture-word interference experiments and in the present Experiment 1. However, when a task decision has to be made, cognitive slack may hide the semantic interference in the model, as observed in the present Experiment 2. The semantic effect disappeared in the model even with random lexical selection latencies with a range of $100 \mathrm{~ms}$. Note that, under the assumption of a post-lexical selection suspension point for the picture-word task, semantic interference will only be hidden if task decisions take longer than the duration of processes up to and including lexical selection in the semantically related condition, as illustrated in Fig. 1. In contrast, if task decisions take less time than the processes up to and including lexical selection (not shown in Fig. 7), semantic interference will be obtained even when a task
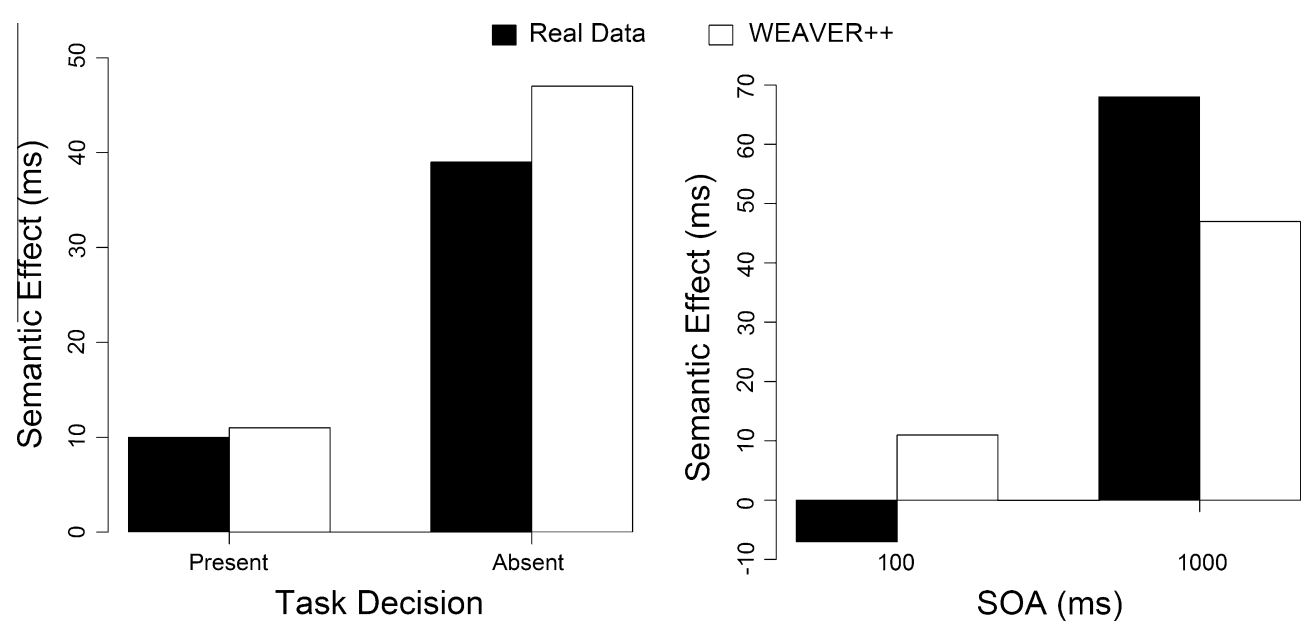

Fig. 7. Difference in mean naming time for semantically related and unrelated distractor words: Real data and WEAVER++ simulation results. Left-hand panel: The effect of task decision (present in Experiment 2 and absent in Experiment 1). Right-hand panel: The effect of stimulus-onset asynchrony (SOA) in the psychological refractory-period procedure (Dell'Acqua et al., 2007). 
decision has to be made, which corresponds to what Janssen et al. (2008) empirically observed. As already noted, the difference between the semantically related and unrelated conditions that needs to be absorbed into the slack is small (30-40 ms). This means that slight differences in the duration of task-decision and picture-naming processes are already enough to render the semantic effect measurable or not. This is indeed the case in the model. If the task-decision process had been, on average, $25 \mathrm{~ms}$ faster than was assumed in the simulations discussed above, a semantic interference effect of $32 \mathrm{~ms}$ occurs in the model (not shown in Fig. 7), which corresponds to what Janssen et al. (2008) observed.

The right-hand panel of Fig. 7 shows the simulation results for the PRP experiment of Dell'Acqua et al. (2007). Their participants had to indicate the height of a tone (low, medium, high) as the first task and name the picture of pictureword interference stimuli as the second task. The distractor words were semantically related or unrelated. We informally chose a tone-discrimination delay of $300 \mathrm{~ms}$ to optimise the fit between model and data. At an SOA of $1000 \mathrm{~ms}$ between the tone and the picture-word stimulus, there is sufficient time for the manual response to the tone to be completed before the onset of the picture-word stimulus. Consequently, cognitive slack is absent in the model and a full-blown semantic interference effect is obtained. However, at an SOA of $100 \mathrm{~ms}$, manual responding creates cognitive slack, which reduces the semantic interference effect in the model. Thus, semantic interference and SOA are underadditive in the model, which corresponds to what Dell'Acqua et al. (2007) empirically observed.

To conclude, the simulation results demonstrate the utility of our theoretical claim that task decision creates cognitive slack and may, thereby, hide semantic interference, explaining the results of the present Experiments 1 and 2. Moreover, the simulations demonstrate that with slightly faster task decisions, semantic interference is revealed, corresponding to what Janssen et al. (2008) observed. In addition, the simulations demonstrate that manual responding may also create cognitive slack and absorb semantic interference in a PRP experiment. Taken together, the simulation results support a unified account of task decision and PRP effects, in line with what Besner and Care (2003) proposed.

\section{Summary and conclusions}

In three experiments, we examined the influence of task decisions on semantic effects in immediate picture naming and the replicability of semantic interference effects in delayed naming. We argued that task decisions may hide or reveal semantic effects in immediate naming depending on the relative speed of task-decision and picture-word processing. In support of this account, we obtained semantic interference in immediate naming in a single-task situation requiring picture naming only. By contrast, no semantic effect in immediate naming was obtained using the task-decision design of Janssen et al. (2008). Finally, no semantic interference was found in delayed naming regardless of the materials, of the proportion of reading and naming trials, and of the presence of task decisions. These results support our task-decision account and provide further evidence for competition in lexical selection.

\section{Acknowledgments}

This research was supported by a grant from the Netherlands Organisation for Scientific Research. The authors thank Hannah Ferentzi and Jil Humann for their help in running the experiments, and the reviewers for their helpful comments.

Appendix A. Materials from Experiments 1 and 3 (English translations between parentheses). Verification words only apply to Experiment 1

\begin{tabular}{|c|c|c|c|c|}
\hline & \multirow[b]{2}{*}{ Target } & \multicolumn{2}{|l|}{ Distractor } & \multirow{2}{*}{$\begin{array}{l}\text { Verification } \\
\text { Different }\end{array}$} \\
\hline & & Related & Unrelated & \\
\hline Animals & $\begin{array}{l}\text { zwaan (swan) } \\
\text { schildpad (turtle) } \\
\text { konijn (rabbit) } \\
\text { hert (deer) }\end{array}$ & $\begin{array}{l}\text { schildpad } \\
\text { zwaan } \\
\text { hert } \\
\text { konijn }\end{array}$ & $\begin{array}{l}\text { rok } \\
\text { beker } \\
\text { arm } \\
\text { bureau }\end{array}$ & $\begin{array}{l}\text { auto/fiets } \\
\text { arm/been } \\
\text { trui/jas } \\
\text { fabriek/molen }\end{array}$ \\
\hline Clothing & $\begin{array}{l}\text { trui (sweater) } \\
\text { rok (skirt) } \\
\text { hemd (singlet) } \\
\text { jas (jacket) }\end{array}$ & $\begin{array}{l}\text { rok } \\
\text { trui } \\
\text { jas } \\
\text { hemd }\end{array}$ & $\begin{array}{l}\text { dolk } \\
\text { zwaan } \\
\text { oor } \\
\text { kasteel }\end{array}$ & $\begin{array}{l}\text { hert/zwaan } \\
\text { kasteel/kerk } \\
\text { dolk/zwaard } \\
\text { schildpad/konijn }\end{array}$ \\
\hline Transportation & $\begin{array}{l}\text { fiets (bicycle) } \\
\text { trein (train) } \\
\text { auto (car) } \\
\text { vliegtuig (airplane) }\end{array}$ & $\begin{array}{l}\text { trein } \\
\text { fiets } \\
\text { vliegtuig } \\
\text { auto }\end{array}$ & $\begin{array}{l}\text { kast } \\
\text { kerk } \\
\text { konijn } \\
\text { glas }\end{array}$ & $\begin{array}{l}\text { kanon/pistool } \\
\text { beker/bord } \\
\text { tafel/kast } \\
\text { rok/hemd }\end{array}$ \\
\hline
\end{tabular}


Appendix A (continued)

\begin{tabular}{|c|c|c|c|c|}
\hline & \multirow[b]{2}{*}{ Target } & \multicolumn{2}{|c|}{ Distractor } & \multirow{2}{*}{$\begin{array}{l}\text { Verification } \\
\text { Different }\end{array}$} \\
\hline & & Related & Unrelated & \\
\hline Buildings & $\begin{array}{l}\text { molen (mill) } \\
\text { kasteel (castle) } \\
\text { fabriek (factory) } \\
\text { kerk (church) }\end{array}$ & $\begin{array}{l}\text { kasteel } \\
\text { molen } \\
\text { kerk } \\
\text { fabriek }\end{array}$ & $\begin{array}{l}\text { kan } \\
\text { jas } \\
\text { neus } \\
\text { been }\end{array}$ & $\begin{array}{l}\text { bureau/bed } \\
\text { neus/oor } \\
\text { glas/kan } \\
\text { vliegtuig/trein }\end{array}$ \\
\hline Weapons & $\begin{array}{l}\text { dolk (dagger) } \\
\text { zwaard (sword) } \\
\text { kanon (cannon) } \\
\text { pistool (gun) }\end{array}$ & $\begin{array}{l}\text { zwaard } \\
\text { dolk } \\
\text { pistool } \\
\text { kanon }\end{array}$ & $\begin{array}{l}\text { trui } \\
\text { tafel } \\
\text { bord } \\
\text { bed }\end{array}$ & $\begin{array}{l}\text { beker/bord } \\
\text { auto/fiets } \\
\text { jas/trui } \\
\text { molen/kerk }\end{array}$ \\
\hline Service & $\begin{array}{l}\text { beker (cup) } \\
\text { kan (pitcher) } \\
\text { glas (glass) } \\
\text { bord (plate) }\end{array}$ & $\begin{array}{l}\text { kan } \\
\text { beker } \\
\text { bord } \\
\text { glas }\end{array}$ & $\begin{array}{l}\text { schildpad } \\
\text { molen } \\
\text { vliegtuig } \\
\text { kanon }\end{array}$ & $\begin{array}{l}\text { dolk/zwaard } \\
\text { neus/oor } \\
\text { been/arm } \\
\text { hemd/rok }\end{array}$ \\
\hline Furniture & $\begin{array}{l}\text { tafel (table) } \\
\text { kast (wardrobe) } \\
\text { bed (bed) } \\
\text { bureau (desk) }\end{array}$ & $\begin{array}{l}\text { bed } \\
\text { bureau } \\
\text { tafel } \\
\text { kast }\end{array}$ & $\begin{array}{l}\text { zwaard } \\
\text { fiets } \\
\text { pistool } \\
\text { hert }\end{array}$ & $\begin{array}{l}\text { konijn/schildpad } \\
\text { kanon/pistool } \\
\text { kasteel/fabriek } \\
\text { vliegtuig/trein }\end{array}$ \\
\hline Body parts & $\begin{array}{l}\text { arm (arm) } \\
\text { neus (nose) } \\
\text { been (leg) } \\
\text { oor (ear) }\end{array}$ & $\begin{array}{l}\text { neus } \\
\text { arm } \\
\text { oor } \\
\text { been }\end{array}$ & $\begin{array}{l}\text { trein } \\
\text { fabriek } \\
\text { auto } \\
\text { hemd }\end{array}$ & $\begin{array}{l}\text { tafel/kast } \\
\text { bureau/bed } \\
\text { glas/kan } \\
\text { hert/zwaan }\end{array}$ \\
\hline
\end{tabular}

\section{Appendix B. Materials from Experiment 2 (English translations between parentheses)}

\begin{tabular}{lll}
\hline Picture name & Related distractor & Unrelated distractor \\
\hline auto (car) & vrachtwagen (truck) & fontein \\
bed (bed) & sofa (couch) & zwabber \\
been (leg) & elleboog (elbow) & sinaasappel \\
berg (mountain) & vulkaan (vulcano) & walvis \\
bezem (broom) & zwabber (swab) & sofa \\
brood (bread) & cracker (cracker) & sigaar \\
dobbelsteen (dice) & kaart (cards) & thermos \\
dolfijn (dolphin) & walvis (whale) & vulkaan \\
eikel (acorn) & kastanje (chestnut) & veerpont \\
fles (bottle) & thermos (flask) & kaart \\
fluit (flute) & gitaar (guitar) & scheen \\
hand (hand) & scheen (shin) & gitaar \\
hark (rake) & schep (spade) & wenkbrauw \\
harp (harp) & viool (violin) & lever \\
hart (heart) & lever (liver) & viool \\
hond (dog) & konijn (rabbit) & ballon \\
kanon (cannon) & pistool (pistol) & enkel \\
kerk (church) & moskee (mosque) & arend \\
kikker (frog) & hagedis (lizard) & bliksem \\
mond (mouth) & wenkbrauw (brow) & schep \\
oog (eye) & enkel (ankle) & pistool \\
paard (horse) & geit (goot) & boor
\end{tabular}


Appendix A (continued)

\begin{tabular}{lll}
\hline Picture name & Related distractor & Unrelated distractor \\
\hline peer (pear) & sinaasappel (orange) & elleboog \\
pijp (pipe) & sigaar (cigar) & cracker \\
put (well) & fontein (fountain) & vrachtwagen \\
regen (rain) & bliksem (lightning) & hagedis \\
schoen (shoe) & want (glove) & worm \\
slak (snail) & worm (worm) & want \\
spijker (nail) & schroef (screw) & koets \\
tafel (table) & bank (bench) & ui \\
trein (train) & koets (carriage) & schroef \\
uil (owl) & arend (eagle) & moskee \\
vaas (vase) & urn (urn) & mossel \\
vis (fish) & mossel (clam) & urn \\
vlieger (kite) & ballon (balloon) & konijn \\
vliegtuig (airplane) & veerpont (ferry) & kastanje \\
wortel (carrot) & ui (onion) & bank \\
zaag (saw) & boor (drill) & geit \\
zon (sun) & komeet (comet) & gans \\
zwaan (swan) & gans (goose) & komeet \\
\hline
\end{tabular}

\section{References}

Baayen, R. H., Piepenbrock, R., \& van Rijn, H. (1993). The CELEX Lexical Database (CD-ROM).

Balota, D., \& Chumbley, J. I. (1985). The locus of word-frequency effects in the pronunciation task: Lexical access and/or production? Journal of Memory and Language, 24, 89-106.

Besner, D., \& Care, S. (2003). A paradigm for exploring what the mind does while deciding what it should do. Canadian Journal of Experimental Psychology, 57, 311-320.

Bonin, P., \& Fayol, M. (2002). Frequency effects in the written and spoken production of homophonic picture names. European Journal of Cognitive Psychology, 14, 289-313.

Coltheart, M., Rastle, K., Perry, C., Langdon, R., \& Ziegler, J. (2001). DRC: A dual route cascaded model of visual word recognition and reading aloud. Psychological Review, 108, 204-256.

Dell'Acqua, R., Job, R., Peressotti, F., \& Pascali, A. (2007). The picture-word interference effect is not a Stroop effect. Psychonomic Bulletin $\mathcal{E}$ Review, 14, 717-722

Desimone, R., \& Duncan, J. (1995). Neural mechanisms of selective visual attention. Annual Review of Neuroscience, 18, 193-222.

Finkbeiner, M., \& Caramazza, A. (2006a). Lexical selection is not a competitive process: A reply to La Heij et al. (2006). Cortex, 42, 1032-1035

Finkbeiner, M., \& Caramazza, A. (2006b). Now you see it, now you don't: On turning semantic interference into facilitation in a Stroop-like task. Cortex, 42, 790-796.

Glaser, W. R., \& Düngelhoff, F. J. (1984). The time course of picture-word interference. Journal of Experimental Psychology: Human Perception and Performance, 10, 640-654.

Glaser, W. R., \& Glaser, M. O. (1989). Context effects in stroop-like word and picture processing. Journal of Experimental Psychology: General, $118,13-42$

Heathcote, A., Popiel, S. J., \& Mewhort, D. J. K. (1991). Analysis of response time distributions: An example using the Stroop task. Psychological Bulletin, 109, 340-347.

Indefrey, P., \& Levelt, W. J. (2004). The spatial and temporal signatures of word production components. Cognition, 92, 101-144.

Jaeger, T. F. (2008). Categorical data analysis: Away from ANOVAs (transformation or not) and towards logit mixed models. Journal of Memory and Language, 59, 434-446.

Janssen, N., Schirm, W., Mahon, B. Z., \& Caramazza, A. (2008). Semantic interference in a delayed naming task: Evidence for the response exclusion hypothesis. Journal of Experimental Psychology: Learning, Memory, and Cognition, 34, 249-256.

Jeannerod, M. (1997). The cognitive neuroscience of action. Blackwell: Wiley.

Jescheniak, J. D., \& Levelt, W. J. (1994). Word frequency effects in speech production: Retrieval of syntactic information and of phonological form. Journal of Experimental Psychology: Learning, Memory, and Cognition, 20, 824-843.

La Heij, W., Kaptein, N. A., Kalff, A. C., \& de Lange, L. (1995). Reducing color-color interference by optimizing selection for action. Psychological Research, 57, 119-130.

Lamers, M. J., \& Roelofs, A. (2007). Role of Gestalt grouping in selective attention: Evidence from the Stroop task. Perception \& Psychophysics, 69, 1305-1314

Levelt, W. J. M., Roelofs, A., \& Meyer, A. S. (1999). A theory of lexical access in speech production. Behavioral and Brain Sciences, 22, 1-75.

Luce, R. D. (1986). Response times. New York: Oxford University Press.

Lupker, S. J. (1979). The semantic nature of response competition in the picture-word interference task. Memory \& Cognition, 7, 485-495.

Mädebach, A., Oppermann, F., Hantsch, A., Curda, C., \& Jescheniak, J.D. (in press). Is there semantic interference in delayed naming? Journal of Experimental Psychology: Learning, Memory, and Cognition.

Mahon, B. Z., Costa, A., Peterson, R., Vargas, K. A., \& Caramazza, A. (2007) Lexical selection is not by competition: A reinterpretation of semantic interference and facilitation effects in the picture-word interference paradigm. Journal of Experimental Psychology: Learning, Memory, and Cognition, 33, 503-535.

Meyer, D. E., \& Kieras, D. E. (1997a). A computational theory of executive control processes and human multiple-task performance. Part 1. Basic Mechanisms. Psychological Review, 104, 3-65.

Meyer, D. E., \& Kieras, D. E. (1997b). A computational theory of executive cognitive processes and multiple-task performance. Part 2. Accounts of psychological refractory-period phenomena. Psychological Review 104, 749-791

Miller, E. K., \& Cohen, J. D. (2001). An integrative theory of prefrontal cortex function. Annual Review of Neuroscience, 24, 167-202.

Norris, D. (1994). Shortlist: A connectionist model of continuous speech recognition. Cognition, 52, 189-234.

O'Craven, K. M., Downing, P. E., \& Kanwisher, N. (1999). FMRI evidence for objects as the units of attentional selection. Nature, 401, 584-587.

Oldfield, R., \& Wingfield, A. (1965). Response latencies in naming objects. The Quarterly Journal of Experimental Psychology, 17, 273-281.

Pashler, H. (1994). Dual-task interference in simple tasks: Data and theory. Psychological Bulletin, 116, 220-244.

Pashler, H., \& Johnston, J. C. (1989). Chronometric evidence for central postponement in temporally overlapping tasks. Quarterly Journal of Experimental Psychology: Human Experimental Psychology, 41, 19-45.

Paulitzki, J. R., Risko, E. F., O’Malley, S., Stolz, J. A., \& Besner, D. (2009). On the role of set when reading aloud: A dissociation between prelexical and lexical processing. Consciousness and Cognition, 18, 135-144

Raaijmakers, J. G. W., Schrijnemakers, J. M. C., \& Gremmen, F. (1999). How to deal with "The language-as-fixed-effect fallacy": Common misconceptions and alternative solutions. Journal of Memory and Language, 41, 416-426. 
Ratcliff, R. (1979). Group reaction time distributions and an analysis of distribution statistics. Psychological Bulletin, 86, 446-461.

Reynolds, M., \& Besner, D. (2006). Reading aloud is not automatic: Processing capacity is required to generate a phonological code from print. Journal of Experimental Psychology: Human Perception and Performance, 32, 1303-1323.

Roelofs, A. (1992). A spreading-activation theory of lemma retrieval in speaking. Cognition, 42, 107-142.

Roelofs, A. (2003). Goal-referenced selection of verbal action: Modeling attentional control in the Stroop task. Psychological Review, 110, $88-125$.

Roelofs, A. (2006). Context effects of pictures and words in naming objects, reading words, and generating simple phrases. Quarterly Journal of Experimental Psychology, 59, 1764-1784.

Roelofs, A. (2007). Attention and gaze control in picture naming, word reading, and word categorizing. Journal of Memory and Language, 57, $232-251$.

Roelofs, A. (2008a). Attention, gaze shifting, and dual-task interference from phonological encoding in spoken word planning. Journal of Experimental Psychology: Human Perception and Performance, 34, 1580-1598.

Roelofs, A. (2008b). Dynamics of the attentional control of word retrieval: Analyses of response time distributions. Journal of Experimental Psychology: General, 137, 303-323.
Rosinski, R. (1977). Picture-word interference is semantically based. Child Development, 48, 643-647.

Schriefers, H., Meyer, A., \& Levelt, W. J. (1990). Exploring the time course of lexical access in language production picture-word interference studies. Journal of Memory and Language, 29, 86-102.

Sigman, M., \& Dehaene, S. (2008). Brain mechanisms of serial and parallel processing during dual-task performance. The Journal of Neuroscience, 28, 7585-7598.

Snodgrass, J. G., \& Vanderwart, M. (1980). A standardized set of 260 pictures: Norms for name agreement, image agreement, familiarity, and visual complexity. Journal of Experimental Psychology: Human Learning and Memory, 6, 174-215.

Starreveld, P. A., \& La Heij, W. (1996). Time-course analysis of semantic and orthographic context effects in picture naming. Journal of Experimental Psychology: Learning, Memory, and Cognition, 22, 896-918.

Stroop, J. R. (1935). Studies of interference in serial verbal reactions. Journal of Experimental Psychology, 18, 643-662.

Van Casteren, M., \& Davis, M. H. (2006). Mix, a program for pseudorandomization. Behavior Research Methods, 38, 584-589.

Yap, M. J., \& Balota, D. A. (2007). Additive and interactive effects on response time distributions in visual word recognition. Journal of Experimental Psychology: Learning, Memory, and Cognition, 33, 274-296. 